\title{
PATRONATOS, PATRONOS, CLÉRIGOS Y PARROQUIANOS. LOS DERECHOS DE PATRONAZGO SOBRE MONASTERIOS E IGLESIAS COMO FUENTE DE RENTA E INSTRUMENTO DE CONTROL Y DOMINACIÓN DE LOS PARIENTES MAYORES GUIPUZCOANOS (SIGLOS XIV A XVI)*
}

\author{
POR
}

\author{
José Ramón Díaz de Durana Ortiz de Urbina
}

Universidad del País Vasco. Vitoria

\begin{abstract}
Resumen
El trabajo aborda el estudio de los derechos de patronato en Guipúzcoa desde su consideración no sólo como fuente de renta de los Parientes Mayores de ese teritorio sino también como un instrumento de control y dominación social y política. He utilizado la documentación judicial del Obispado de Pamplona, de la Chancillería de Valladolid y de los concejos guipuzcoanos para abordar las siguientes cuestiones: (i) el analisis del origen y las formas de apropiación de los derechos de patronato, (ii) las rentas derivadas de los mismos y (iii) los enfrentamientos entre patronos y partoquianos en tomo al nombramiento de los clérigos, el reparto de los diezmos y demás ingresos asociados a las iglesias o a la ubicación en el interior de las mismas de los feligreses tanto durante su vida como después de la muerte.
\end{abstract}

\section{Abstract}

In this paper we examine patronage rights in Guipuzcoa not only as sources of income for "Parientes Mayores" (Heads of Noble Houses) in that area, but also as instruments of social and political control and domination. Judiciary do-

\footnotetext{
- Este trabajo forma parte de los resultados de un proyecto de investigación (UPV 156.130HA064/97 y G.V. P1997/63) financiado por la Universidad del Pais Vasco y el Gobiemo Vasco “ De los Bandos a la Provincia: Transformaciones econ6́micas, sociales, políticas y culturales en la Guipúzcoa de los siglos XIV a XVI". Reune a un grupo de ocho investigadores de los Departarnentos de Historia Medieval, Modema y América, Historia e Instituciones Económicas y Filología Española de la UPV/EHU.
} 
cuments from Pamplona's bishopric, from Valladolid's Chancellery and from Guipuzcoan councils were studied and used to analyze the following: (i) the origin and ways of appropriation of patronage rights, (ii) the revenues derived from them and (iii) conflicts between patrons and parishioners around clergymen appointments distribution of tithes and other revenues pertaining to churches and the physical location parishioners occupied inside church buildings both during their lifetime and after death.

El estudio de los derechos de patronazgo sobre las iglesias es un viejo problema que ha ocupado de un modo intermitente a los historiadores. No aspiro, sin embargo, a continuar el camino de los análisis realizados hasta la fecha sobre los distintos aspectos que rodean a las llamadas iglesias propias'. Pretendo simplemente observar el origen y evolución de aquellos derechos en Guipúzcoa, desde el convencimiento de que su examen constituye una excelente guía para explicar y entender las transformaciones sociales, económicas, políticas y culturales que tienen lugar en la sociedad guipuzcoana durante los siglos XIV a XVI y especialmente cuando estaban en manos de los Parientes Mayores, de los jefes de linaje de las principales casas de la nobleza guipuzcoana $^{2}$. En efecto, entre las fuentes de renta de éstos últimos, las procedentes

' La observación se ha producido fundamentalmente desde la Historia del Derecho y para la etapa altomedieval. Entre otros autores es necesario recordar a M. TORRES LóPEZ, "La doctrina de las "Iglesias propias" en los autores españoles", $A H D E, 2,(1925)$, pp. 402-461; del mismo autor "El origen del sistema de "Iglesias propias", $A H D E, 5,(1928), p p, 83-217$. El amplísimo artículo de A. GarCia Gallo, "El Concilio de Coyanza. Contribución al estudio del derecho canónico español en la Alta Edad Media", $A H D E, 20,(1950), p p .275$ a 633. También el de Victor de REjNA, "Contribuciones al estudio del "ius episcopale" en los monasterios particulares e Iglesias propias según los documenios de Irache", $A H D E, 34,(1964), p p$. 547-564. Otros autores que han abordado cl problema desde distintos ángulos y para otros ámbitos territoriales serán citados en las notas a pie de página que siguen a continuación.

2 Remito al lector a la definición que J. Caro Baroja ofrece en su "Linajes y bandos" sobre los Parientes Mayores: "...disfrutaban de una serie de atribuciones reconocidas y les caracterizaba un modo de vivir especial hasta cierto punto. Aparte de poseer mayor proporción de bienes raíces y de otra índole sus mismas mansiones eran corres fortificadas a las que se conocía con el nombre de mansión del señor - jaureguia...El Pariente Mayor era el que daba permiso a los demás para que usaran las armas y los escudos del linaje...El Pariente Mayor era también cabeza de patronatos familiares sobre ermitas, iglesias o partes de éstas, presidia cofradias piadosas vinculadas a ellas y a su voz se ponían en pie de guerra todos los miembros del linaje y de los linajes emparentados. En Vasconia$n a$, edición 1974, pp. 31 y 32. Por otra parte, I. AROCENA, ha abordado la cuestión en "Los Parientes Mayores y las Gueras de Bandos en Gujpúzcoa y Vizcaya", en Historia del Pueblo Vasco, I, San Sebastián, 1978, págs. 151 a 172. Ambos autores han detallado la composición y el funcionamiento interno de esas complejas agrupaciones. Cada uno de los linajes aglutinaba un numeroso grupo de gentes, presidiđa por un Pariente Mayor. Este lo era también de la familia principal del mismo, cuyo solar y casa-torre, fundado por un antepasado común, y el apellido correspondiente al topónimo del solar, daban nombre al linaje o, en su caso, al grupo de linajes. Estos contribuían con sus bienes y su

La época de Felipe II y los Austrias

Hispania Sacra 50 (1998) 
de los patronatos, es decir, de los diezmos, primicias y ofrendas que entregaban los parroquianos de las iglesias de las villas y lugares que estaban bajo su patronazgo así como de otros bienes asociados a las mismas, fueron seguramente una de las más importantes y saneadas. Pero, además, el patronazgo sobre una parte importante de las iglesias guipuzcoanas, no sólo de las ubicadas en el mundo rural sino también de las parroquias de algunas villas y de modo particular de aquellas fundadas durante el siglo XIV, fue también, como en el caso de los molinos o de las rentas de la tierra, un instrumento de control y dominación no sólo económico sino también social e ideológico, en definitiva, político. El objetivo de estas líneas es precisamente analizar los distintos aspectos señalados hasta ahora en una visión diacrónica que tenga en cuenta el origen de los derechos de patronazgo sobre las iglesias, la titularidad de los Parientes Mayores sobre los mismos y su evolución durante los siglos XIV a XVI, de modo que pueda observarse la conflictiva relación que se establece entre patronos y parroquianos especialmente desde el momento en que la relación de fuerzas entre ambos se decanta a favor de los últimos al compás de las transformaciones sociales y políticas que se producen en Guipúzcoa desde mediados del siglo XV. De este modo será posible entender por qué durante el siglo XVI, lejos de debilitarse o de desaparecer, la institución mantuvo su fortaleza y pese a una relativa ampliación del abanico de posesores de patronatos, limitada a los más significados miembros de las nuevas élites guipuzcoanas, los herederos de los Parientes Mayores continuaron conservando las rentas y privilegios que habían defendido sus ancestros durante el siglo XV.

La documentación para analizar las cuestiones planteadas es muy abundante gracias a las tensiones entre patronos y parroquianos al final de la Edad Media. Procede, por este orden, del Archivo de la Real Chancillería de Valladolid, del Archivo Diocesano de Pamplona y de los fondos documentales de los distintos concejos guipuzcoanos. En todos ellos están depositadas piezas correspondientes a los pleitos planteados tanto ante las autoridades eclesiásticas como ante las civiles y tanto por los señores como por los concejos o por los parroquianos afectados. Los primeros intentando mantener unos privilegios

influencia sobre los hombres al engrandecimiento del linaje siempre a las ordenes del Pariente Mayor, figura sobre la que recaía la defensa, administración y acrecentamiento del patrimonio familiar y a cuya voz se ponían en pie de guerra todos los miembros del linaje y de los linajes emparentados. Los linajes integraban no solo a aquellos que estaban unidos por lazos de sangre en diversos grados, sino también a otras gentes vinculados por lazos de dependencia personal o colectiva. Una de estas formas de vinculación son los atreguados, que a cambio de su participación en la guerra recibían protección del Pariente Mayor. Otra forma de vinculación es la encomienda, en la que la contraprestación a cambio de la protección era económica y normalmente impuesta por la fuerza. Por último se vinculaban al Pariente Mayor acotados de la justicia en busca de refugio, autores habituales de los hechos violentos denunciados por los campesinos y las gentes de las villas. 
que los segundos pretendían limitar y no sólo aquellos relacionados con las rentas, sino también con la preeminencia social que implicaba. Algunos episodios relacionados con estos enfrentamientos, como el incendio de los bancos ocupados por los Parientes en los lugares más destacados de distintas iglesias, pueden ser considerados como un episodio más de las luchas antiseñoriales protagonizadas por los vecinos de las villas y lugares guipuzcoanos en el tránsito del Cuatrocientos al Quinientos.

\section{El PATRONAZgo DE LOS SEÑoRes DE OÑAZ Y LOYOLA SOBRE SAN SEBASTIÁN DE SOREASU EN AZPEITIA.}

Los ejemplos del ejercicio de los derechos de patronazgo sobre distintas iglesias guipuzcoanas son numerosos. A lo largo de estas páginas se analizarán en los momentos más importantes de su evolución pero, a modo de introducción, considero de interés singularizar uno de esos casos para enmarcar el tema y los problemas que propongo estudiar. Se trata del patronato que sobre el monasterio de Soreasu alcanzaron los señores de Oñaz y Loyola ${ }^{3}$. Su historia puede resultar representativa de la evolución del conjunto de las iglesias guipuzcoanas bajo patronato laico durante los siglos XIV a XVI. El monasterio de San Sebastián de Soreasu, de patronato real, fue entregado por Fernando IV a los vecinos de Salvatierra de Iraurgui (Azpeitia) en 1311 a cambio de 1000 maravedis anuales ${ }^{4}$. En 1394, sin embargo, Enrique III de Castilla, lo entregaba a Beltrán Ibañez de Loyola, señor del solar de Oñaz y Loyola: “...por los

\footnotetext{
${ }^{3}$ Para desarrollar este ejemplo he consultado la tesis doctoral, aún inédita, de J. Antonio MARÍN, "Semejante Pariente Mayor". Parentesco, solar, comunidad y linaje en la Institución de un Pariente Mayor en Gipuzkoa: "Los Señores de Oñaz y Layola cuya es la casa de Loyola" Siglos XIV$X V T^{\prime \prime}$. Fue defendida el 6 de Julio de 1996 en la Universidad de Deusto en San Sebastián, abteniendo la máxima calificación.

4 G. Martínez Diez, E. Martínez dízz, F. J. Martínez llorente, Colección de Fuentes Documentales de las villas guipuzcoanas, (1200-1369), San Sebastián, 1991, pp. 113-114: “...a los pobladores que agora y sson commo a los que sserán daqui adelante, porque este logar sse pueble mejor e más ayna e de mejores omnes, veyendo e entendiendo que es mío sseruiçio, tengo por bien de les dar el mío monasterio de Ssorearssu con montes e con ffuentes e con ssus heredamientos e con sus pastos e con todos los derechos que a este monasterio pertenesçen e deuen pertenesçer, que lo ayan libre e quito para syenpre jamás por iuro de heredat, en tal manera que por rrazb́n de los derechos que yo y ssolla auer ffasta aqui que me den daqui adelante por ssyenpre jamas a mi $e$ a los rreyes que venieren después de mi, cada anno por el Sant Martín de nouiembre, mill marauedís de la moneda nueua que yo mandé labrar a diez dineros el marauedi; e que sse aprouechen los pobladores deste logar de todos los heredamientos e déçimas e derechos que al dicho monasterio pertenesçen assy commo de las sus cosas mismas, saluo que lo non pueden vender nin camiar nin dar nin enagenar a omne de rreligión nin de orden nin a omne que ssea de ffuera del mio sennorio, porque sse enagenas $[$ e] del mío ssennorio...".
}

La época de Felipe II y los Austrias

Hispania Sacra 50 (1998) 
muchos buenos e leales serviçios que fesisteis al rey don Juan...et fasedes eso mismo a mi de cada dia, fago vos merced del mi monasterio rreal de San Sebastian de Soreasu con todas las deçimas e rentas e derechos e terminos e heredades e con todas las otras cosas que al dicho monasterio pertenesçen e pertenescer deven asi de fecho como de derecho, el qual dicho monasterio...vos fago merçet del por juro de heredat para siempre jamas para vos e para los que de vos descendieren por linia derecha e lo vuestro ovieren de heredar..."5.

An̄os más tarde, en 1407, D. Beltrán tuvo que recurrir de nuevo al monarca para que interviniera protegiendo sus derechos mediante la intervención del merino mayor en Guipúzcoa Ferrán Pérez de Ayala “...porque los desmeros del dicho monasterio non le renden complidamente con los diesmos e rrentas $e$ derechos que al dicho monasterio pertenescen e pertenescer deven, antes dise que maguer él ha la bos e la fama que se llieva calladamente los diesmos e el provecho del dicho monesterio un clérigo que llaman Pelegrin Gomes que y dis que es puesto por el Cardenal de Pamplona..." 6 . 0 , dicho de otro modo, trece años más tarde, tanto el Obispo de Pamplona, bajo cuya tutela se encontraba el monasterio, como los parroquianos continuaban disputando el patronato y las rentas a D. Beltrán. Estas últimas, al parecer, no habían sido todavía suficientemente valoradas, de modo que fue necesario nombrar tres hombres buenos para que "...aprescien e estimen sobre jura todos los trigos e cevadas $e$ avenas e mijos et linos e mançana e todas las otras cosas que se usan desmar e declaren que es que cada uno deve desmar de cada cosa; e fased recurrir al dicho Beltran Yanes o al que el lo oviere de aver con todo el diesmo de las cosas sobredichas...en guisa que se le non pueda encobrir alguna cosa..."?

Pero el obispo y los parroquianos no eran los únicos que rivalizaban por los derechos sobre el monasterio de Soreasu a los Oñaz y Loyola. El linaje de Emparan se consideraba también con alguna ascendencia sobre los mismos y en particular sobre el nombramiento de los clérigos cuando se producían vacantes. Derechos a los que no renunciaron hasta 1435 con motivo de la tregua acordada entre los Parientes Mayores de ambos linajes, Lope García de Lazcano y Martín Pérez de Emparan ${ }^{8}$. Finalmente, el patronazgo sobre Soreasu se

\footnotetext{
${ }^{5}$ La documentación sobre Soreasu ha sido publicada por C. DALMASES, Fontes documentales de S. Ignatio de Loyola. Monumenta Historica Societate Iesu, vol. 115, Roma, 1977, pp. 16-17.

6 Ibidem, p. 21.

7 lbidem, p. 22

8 Ibidem, p. 101. "...Otrosy, yo, el dicho Martin Peres, otorgo e conosco que yo nin los dichos mis parientes de Enparan nin el dicho solar non avemos derecho alguno de patronadgo para presentar a la dicha yglesia de San Sebastión vycario nin abad nin otro clérigo alguno, e quc vos, el dicho Lopez García, e el dicho vuestro solar de Loyola, e vuestros subcesores quel dicho solar heredaren e ovieren, avedes el patronadgo de la dicha yglesia de San Sabastián para presentar a ella vycario o abad o clérigo, como mejor se deve...".
} 
incorporó al mayorazgo de los Oñaz y Loyola9. Pero las tensiones con el Obispo de Pamplona y, sobre todo, con los parroquianos de Soreasu, vecinos del concejo de Azpeitia, continuaron. Durante las dos últimas décadas del siglo $\mathrm{XV}$, fruto sin duda de las nuevas circunstancias políticas, los patronos de Soreasu y otras iglesias tuvieron que dedicar todas sus energías a defender sus viejos privilegios. La cesión de una parte de los ingresos procedentes de los parroquianos les permitió mantener sus derechos de patronazgo prácticamente intactos ${ }^{10}$. Los Oñaz y Loyola, amparándose en ellos, lograron, en palabras de Marín Paredes, "dejar nítidamente distinguida su ubicación en la comunidad de vecinos de Salvatierra"11. Al tiempo, gracias a los ingresos procedentes del patronato, en los primeros años del siglo XVI, mantenían a los suyos ${ }^{12}$.

Los Parientes Mayores conservaron en lo sustancial sus viejos privilegios durante el siglo XVI: presentación de los clérigos, percepción de los diezmos, primicias y pies de altar, etc. o la ocupación de un lugar preeminente en la iglesia. Sin embargo, las referencias habían cambiado radicalmente. No sólo la jurisdicción eclesiástica se había fortalecido ${ }^{13}$. También, especialmente, las nuevas circunstancias políticas, tanto a nivel provincial como local, habían dado un giro radical a las relaciones de los patronos con los concejos y la Provincia. Buena prueba de ello es un episodio que tuvo lugar en Azpeitia ciento setenta años después de que D. Beltrán recibiera de Enrique III el patronato sobre Soreasu. Un incidente inimaginable en aquella fecha del que tenemos noticia gracias a la demanda presentada por el alcalde de Azpeitia en 1564 contra el rector y beneficiados de la iglesia parroquial de San Sebastián de Soreasu ${ }^{14}$. Los antecedentes de esta demanda tienen su origen en una reyerta que tuvo lugar en el interior de la iglesia de San Sebastián durante la cual el alcalde y el rector de la iglesia, junto a sus acompañantes, se enzarzaron en una pelea que terminó con una cruz ceremonial del concejo rota en varios pedazos

9 Ibidem, p. 73. Así consta al menos en el testamento de Sancha Ibáñez đe Loyola (1464): "...Otrosy retyficolo e apruebo la donaçión que yo e el dicho Lope Garçia, mi marido, equalquier de nos por e en nombre del otro...al dicho Juan Peres fijo mayor ...en que le donamos la casa e solar $e$ mayorazgo de Loyola e Monesterio de Sant Sebastyán de Soreasu con su patronasgo e diesmos e ofertase con todas sus pertenençias e anexos e conexos al dicho mayorasgo e monesterio..."

$10 \mathrm{lbidem}, \mathrm{pp}, 130-132$. Se trata de un reparto de los diezmos entre el patrono y los clérigos (1490).

"I J.A. MARÍN, "Semejante Pariente Mayor"..., o.c., p. 327.

12 A. Real Chancillería de Valladolid, Pleitos Civiles, Quevedo, Fenecidos, C 1282/3 (1509). Se trata de la declaración de un testigo en el pleito entre el rector de Soreasu, Juan de Anchieta, y el patrón Martín García de Oñaz. Este pleito constituye la base del trabajo de L. FERNÁNDEz, "Los señores de la casa de Loyola, patronos de la Iglesia de San Sebastián de Soreasu", en BRSBAP, 1986, pp. 493-522.

13 C. Dalmases, Fontes.., o.c., pp. 148-155. Promulgación de las constituciones sinodiales otorgadas a la clerecía del arciprestazgo de Guipúzcoa por el obispo de Pamplona (1499).

${ }^{14}$ Archivo Diocesano de Pamplona, C. 3 n 8 (1564)

La época de Felipe Il y los Austrias Hispania Sacra 50 (1998) 
al igual que la vara de justicia del alcalde ${ }^{15}$. El telón de fondo de semejante altercado en lugar sagrado fue el uso indebido de la cruz "...de mucho gasto para acrecentar el culto divino..." que habían hecho a su costa los vecinos y parroquianos de la dicha villa. Al parecer el concejo había ordenando "...que la dicha cruz no se aya de sacar ni azer autos con ella por personas particulares y que se guarde para las fiestas prinçipales mas solemnes de todo el año...". Sin embargo, contraviniendo la ordenanza y la costumbre --"...que la cruz cubierta de velo negro se suele solamente poner en los ofiçios de viernes santo y en memoria de la pasion del redentor del mundo y no se deben tener las dichas honrras y cerimonias en osequios ni oficios de otros difuntos..."el rector de Soreasu, para más señas Hernando de Loyola, y el resto de los clérigos utilizaron la cruz para trasladar el cuerpo de Juana de Recalde desde la casa de Loyola hasta la iglesia y finalmente, ocho meses más tarde, “...el dia de Lázaro...tomaron...la dicha cruz con otra de la dicha iglesia para acer ciertas onras e esequias por doña Juana de Recalde...", señora de Loyola. Para el alcalde de Azpeitia no había duda de "...que para las honrras de la dicha doña Jhoana de Recalde vastaba una cruz y aun aquella non debia de estar cubierta de velo negro porque es cirimonia superfula y reservada para el viernes santo..." 16 .

15 Ibidem:"...mandó el dicho alcalde quitar la dicha cruz prinçipal que estaba en parte cubierta y los brapos della parecidos e queriéndola quitar para bolberla a su lugar debido, acudió el dicho don Hernando de Loyola rector y se asió con el dicho alcalde gue tenía la dicha cruz e le dió muchos enpentones por quilarlo della y le quebró la vara real que tenia en su mano e abiendo pedido el dicho alcalde fabor a la justiçia de la dicha fuerça que le hazian acudieron contra el los dichos don Juan de Altuna y don Juan Lopez de Çuola y don Juan de Egurça y don Lorenço de Barrasoeta y don Martin de Landeta y otros clérigos en favor dellos y asieron de la dicha cruz de lo alto de los dos braços della y sin embargo del dicho alcalde anduvo con todo comedimiento los dichos don Juan de Altuna $e$ don Juan Lopez asidos de la dicha cruz la quebraron $e$ hizieron tres o quatro pedaços con muy grande escandalo del pueblo y menos preçio de la reberençia que se debia a la cruz y culto divino de lo qual esta recebida informacion...". La versión de los clérigos es sustancialmente coincidente y confirma la gravedad de los hechos pero proporciona otros datos de interćs:"...el dicho Pedro de Huranga e sus consortes fueron a la dicha iglesia a hora de bisperas y entrando por la iglesia el dicho Pedro de Huranga con mucha soberbia y alboroto a haltas vozes dixo que se avia de quitar de donde estava la dicha cruz mayor y arremetió para la quitar pidiendo fabor $e$ apeliando la boz del rey dentro de la dicha iglesia para quitar la dicha cruz de donde estaba e con mucho desacato y menosprecio del lugar...asió de la cruz y aviendo acudido para la defender el dicho rector pidí favor $e$ ayuda a los dichos beneficiados e capellanes que con los sobrepellices e avito sacerdotal estaban sin ningunas armas en el coro para començar a deçir viespras y para cuando los dichos beneficiados acudieron el dicho alcalde y consortes con enpetones le ronpieron el sobrepeliz al dicho rector y quebraron la cruz e la hizieron muchos pedaços...y el dicho alcalde dixo que aunque pesase al dicho rector e beneficiados avia de ser aquello asi aunque el supiese por ello perder la vida e entregó la dicha cruz a Juan Martinez de Emparan..."

16 Ibidem. 
La iniciativa de impedir el uso de la cruz ceremonial en las honras fúnebres de la señora de Loyola tuvo su origen en el concejo de Azpeitia. El alcalde y el resto de los oficiales no dudaron en imponer su voluntad frente al rector de Soreasu aunque para ello fue necesario utilizar la fuerza. El significado de esta intervención concejil en asuntos relacionados con el patrón de la iglesia y sus derechos en Soreasu es un episodio más del proceso que se inició desde el momento en el que, a finales del siglo XV, el concejo, con el apoyo de la Corona, "se entremetió en la custodia del buen cumplimiento del patronato"17 que era un bien cedido por ésta última desde 1394. En 1579, continuando con una cadena que se prolongó durante el siglo siguiente, se produjo un nuevo enfrentamientro entre patrón y parroquianos ${ }^{18}$.

\section{ORIGEN Y FORMAS DE APROPIACIÓN DE LOS DERECHOS DE PATRONAZGO DE LOS PARIENTES MAYORES SOBRE LAS IGLESIAS GUIPUZCOANAS.}

El ejemplo de Soreasu y los Oñaz y Loyola ha introducido las coordenadas espaciales y temporales en las que se desarrollará el estudio y ha anunciado de algún modo las preguntas necesarias para resolver el problema planteado: los patronatos como fuente de renta e instrumento de control y dominación para los Parientes Mayores gujpuzcoanos. Es hora de contestarlas y, en primer lugar, aquellas relacionadas con el origen de la ascendencia de los Parientes sobre las iglesias. Sobre el particular es muy conocida la tesis mantenida por Lope García de Salazar acerca de "Como fueron poblados e ganados los monasterios e yglesias de las montañas", es decir, el fundamento en el que se apoyaban los derechos de los hidalgos en general y de los Parientes en particular sobre las iglesias: la escasez de estas últimas en las tierras norteñas donde se habían asentado las gentes que huían de los musulmanes ${ }^{19}$. Pero ésta no era

17 J.A. MARín, "Semejante Pariente Mayor"..., o.c., p. 321.

18 A. OTAZU, El "igualitarismo" vasco. Mito y realidad, San Scbastián, 1973, pp. 81 -82.

${ }^{19}$ Libro de las Bieandanzas e fortunas, Angel RODRíGUEZ HERRERO editor , Bilbao, 1967, tomo IV, pp. 429-430.:"...Estas tierras fueron pobladas por gentes benedisas, $e$ fueron echados de sus heredamientos por los moros...e vivian derramadas e no ayuntadas las pueblas, ca no poblaron villa en grandes tiempos. $E$ por falta de iglesias, cataron entre si personas renedores e deligentes que en ciertos logares hedificasen iglesias e monestcrios porque en ellas se cantasen misas, e se resasen las oras, e se diescn los sacramentos segund la Santa Madre Yglesia, e oviesen sus enterramientos, aunque al principio no se ençerrauan dentro dellas sino fuera, en sus sepulcros de piedra, como en muchos logares pareçen oy dia. E por que aquelllos que las tales yglesias hedificaron. compliesen todos estos ornamentos e mantuviesen sendos clerigos en cada una, dieron les un diesmo en cada año de todos los frutos, e cosas que Dios les diese para ellos,... E moriendo estos tales hedificadores de monasterios, e quedando sus herederos, ordenaron de dar al mayor fijo heredero aquel monasterio con aquellas deçimas, por que non se deviese en sus erederos. E porque compliese todas aquellas

La época de Felipe II y los Austrias

Hispania Sacra 50 (1998) 
la única. Aún más, seguramente Lope repetía argumentos utilizados antes por otros en la defensa de sus derechos. En primer lugar, casi un siglo antes, en las Cortes de Guadalajara, se estableció la justificación central y probablemente la más utilizada en la época. Fue la que, según el profesor José Luis Martín, presentó ante Juan I el cronista Pero López de Ayala, encargado de responder a los obispos y clérigos que presentaron sus agravios porque en la tierra de Vizcaya, Álava y Guipúzcoa había iglesias en las que cobraban los diezmos los señores laicos que, además, se reservaban el derecho de nombramiento de los clérigos haciendo caso omiso de las disposiciones canónicas ${ }^{20}$. En segundo lugar, coincidiendo básicamente con los argumentos anteriores, pero esta vez en el ámbito navarro-aragonés, resulta también de interés destacar como, los señores de Murguía, en 1414, utilizaron similares argumentos a los citados como prueba del origen de su patronazgo sobre la iglesia de Santa María de Astigarraga: un privilegio de Urbano II (1088-1099) a Pedro I (1094-1104), monarca al que en ese momento pertenecían las tierras orientales guipuzcoanas, en el que se confirmaba al rey el derecho a percibir los diezmos de aquellas iglesias que adquiriera en tierra de moros o fundara en sus heredades ${ }^{21}$. En

cosas quel tal hedificador avia cumplido, e llamaronle Patron de aquel morasterio. $E$ en algunos dellos los llamaron Abad del monasterio. $E$ mandaronles que de lo que sobrase de aquellas decimas, cumplidos los dichos ornamentos, e su mantenimiento, que diesen sendos yartares, en el anno, a aquellos sus hormanos, e descendientes ea estos yantares llamaron devisa. E dcspues, como la gente fue multiplicando, e suçedieron Reyes e ovieron de partir con ellos estos dichos monasterios, e fueron llamados patrones mayores como lo son oy dia...E despues desto, multiplicando mucho mas las gentes, $e$ los reyes por acreçentar Sennorios, a petiçion de las gentes, poblaron villas grandes $e$ pequeñas. E a los que poblaron en los terminos de aquellos sus monesteorios, dieron a las Yglesias que las tales villas fasian parte de aquellos monasterios para mantenimiento de sus clerigos...".

20 Pedro Lopez de Ayala. Crónicas. Edición, prólogo y notas de José Luis MARTín, Barcelona, 1991,pp. LIX-LX.. Los caballeros reconocieron efectivamente que percibían los diezmos y nombraban a los clérigos desde hacia cuatrocientos affos, "de guando los moros ganaron e conquirieron a España, e los fijos-dalgo, algunos que escaparon de la tal pérdida, alzáronse en las montañas, que eran hiermas e muy fuertes e non pobladas e alli se defendieron de los moros... e para se mejor defender, ordenaron que todos oviesen en sus comarcas ciertos cabdillos a quien fuesen obedientes, $e$ estuviesen por sus mayores en las peleas que con los moros avian; e para mantenimiento de aquel cabdillo o cabdillos, por las costas que facia quando se ayuntaban con él, ordenaron que todos le diesen un diezmo de todo to que ellos labrasen, $e$ estonce non avia Iglesia ninguna poblada en aquella tierra.... y para que no desapareciera la cristiandad, el caudillo nombra y mantiene uno o varios clérigos y ugracias a Dios, ellos se defendieron de los moros e ayudaron al servicio de los reyes sus señores, en manera que echaron los moros de la tierra e la conquistaron e ganaron, $e$ fincaron ellos en aquella posesión de levar los talas diezmos e mantener los clérigos fasta aqui...". Adviértase que el de Ayala era un excelente conocedor de la realidad de esos territorios y en particular de Guipúzcoa, donde había ejercido como Merino Mayor.

${ }^{21}$ Archivo Diocesano de Pamplona, Caja 2422, $\mathrm{n}^{\mathrm{a}} 1$ (1422): “....statuimus tibi carissime filii Petre tuique regni subessonum ex genere tho rite substituendi iuris esse ut ecllesias villarun tan in sarraçenorum terris capere potueritis quam earum quas ipse in regno vestro hedificare feçeritis vel 
todo caso, independientemente del origen, las Partidas habían recogido con extensión y detalle suficientes tanto el significado como el ejercicio de los derechos de patronazgo ${ }^{22}$.

Por otra parte, distinguía Lope García de Salazar dos tipos de iglesias: aquellas que estaban bajo su patronato por haber sido directamente creadas por los hidalgos, las llamadas iglesias diviseras, y las que, procedentes del patronato real, habían obtenido los Parientes Mayores a través de mercedes en las que se incorporaba la administración de los derechos de patronazgo. Sin embargo, estas donaciones no se generalizaron hasta finales del siglo XIV, después del enfrentamiento entre los hidalgos y los prelados en las Cortes de 1390. La justificación histórica y jurídica de los hidalgos sobre Ja percepción de los derechos de patronato se siguió de un duro ataque a los obispos. Argumentos que seguramente conocían los señores de Murguía y Astigarraga cuando defendieron sus derechos al igual que Lope García de Salazar cuando escribió sus Bienandanzas. Tesis que sin duda colaboró a que el resultado del debate, favorable a los hidalgos, a través de las correspondientes mercedes, se tradujera en la confirmación por la Corona de los patronatos a cambio de sostener el culto ${ }^{23}$.

En el caso guipuzcoano, salvo error, la noticia más temprana de la cesión de derechos de patronato sobre monasterios o iglesias ${ }^{24}$, corresponde a los Guevara. Probablemente el patronazgo sobre San Miguel de Oñate es anterior a 1305, fecha de la famosa permuta realizada con Fernando IV en la que, a cambio de varios collazos en Álava, recibió varios monasterios guipuzcoanos sobre los que desde entonces tuvo derechos de patronazgo y en particular sobre Santa Marina de Oxirondo y San Juan de Usarraga ${ }^{25}$. Sin embargo, a fina-

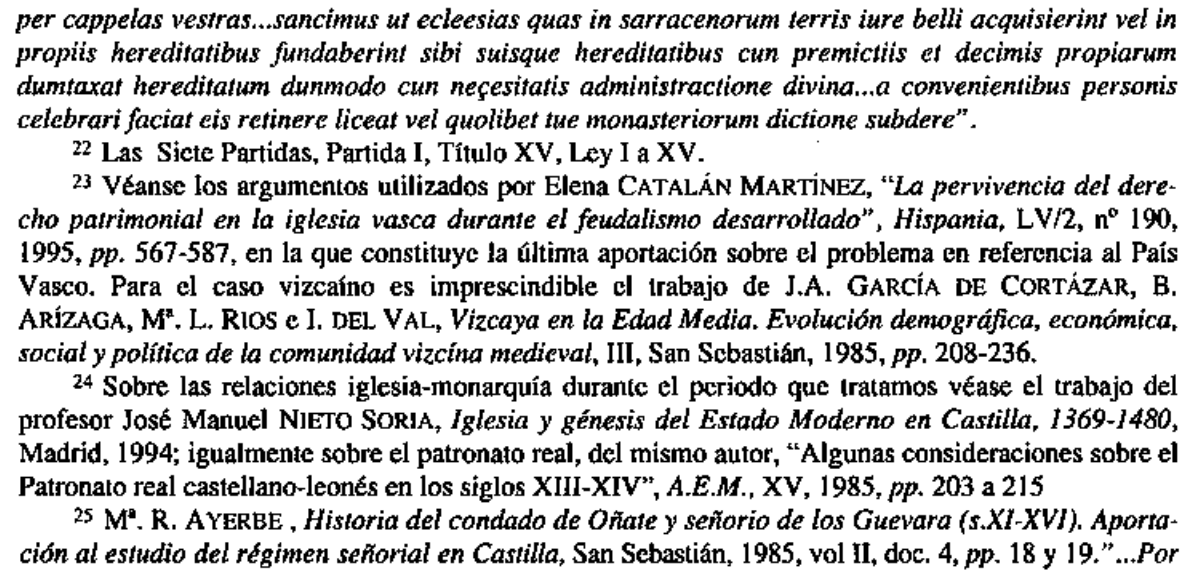


les del siglo XIII y en los primeros años del siglo XIV, todo parece indicar que aún no se había generalizado la concesión de esos derechos sobre las iglesias. Buena prueba de ello es que, en 1292, el obispo de Pamplona y el preboste, alcalde y jurados de la villa de San Sebastián acuerdan la forma en que se ha de hacer el pago de las primicias y la provisión de raciones y beneficios en las iglesias de la villa, todas bajo patronato del concejo ${ }^{26}$. Recuérdese también que, en 1311, Fernando IV entregaba a los vecinos de Azpeitia el monasterio de Soreasu a cambio de 1000 maravedis anuales ${ }^{27}$.

Por otra parte, merece ser destacada la dificultad de discernir en ocasiones si nos encontramos ante una iglesia propia asociada a un linaje hidalgo o ante una iglesia de patronato real. Así, por ejemplo, todo parece indicar que una iglesia como Santa María de Balda estaba asociada al linaje del mismo nombre. Es bien conocido incluso que esa asociación parece desprenderse de la

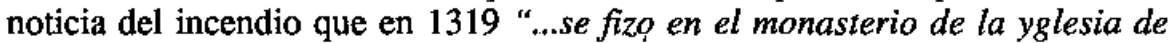
Balda e en las casas que eran cabo ella diziendo que pusieron fuego a ella al tiempo que los de Onnaz mataron a Don Juan Martinez de Balda e a Pero Ybannes su fijo e a los otros sus parientes ...". Sin embargo, en 1331, los futuros pobladores de Azcoitia, quizá tratando de obtener la misma concesión que sus vecinos de Azpeitia, solicitaron a Alfonso XI que les “...diese los terrenos del mio monasterio de Santa Maria de Valda para fazer y sus huertas e para lo que oviese menester...", buena prueba, pese a su nulo éxito, de que aún permanecía bajo tutela real ${ }^{28}$. Lo mismo sucede en el caso de los señores de Murguía que argumentan la inmemorialidad de sus derechos sobre Santa María

ende nos, hauiendo grana sabor de yr por esta carrera adelantre, queremos que sepan por este nuestro preuilegio los que agora son y serán d'aquí adelantre, cómo nos donFernando, par la gracia de Dios rrey de Castiella, de Toledo, de León, de Gallicia, de Seuilla, de Córdoua, de Murcia, de Jahên, del Algarue y señor de Molina, en vno con la reina doña Costanza, mi muger, por facer bien y merced a donBeltrán Yuáñez de Gueuara, sennor d'Oñat, nuestro vasallo, y por mucho seruicio que nos fizo y face, dámosle los nuestros monasterios que nos auemos en tierra de Guipuzca que son estos que aquí serán dichos: Osirundos, Yzarraga, Harriaja, Soreaso, Caraoz. Et dámosgelos bien y complidamientre con todos los pobladores que agora y son y serán daquí adelantre y con todos los fueros y derechos que nos y auemos y auer deuemos, con fuentes y con montes y con ríos y con pastos y con entradas y con salidas y con todas sus perfenencias, quantas an y auer deuen. Et otorgámosle que los aya libres y quitos por jur de heredat, pora siempre jamás, pora êl y pora sus fijos y pora sus nietos y pora otros qualesquier que lo sudo outeren de heredar, para dar y vender y empeñar y camiar y enagenar y pora facer dellos y en ellos rodo lo que quisiere asi como de lo sudo mesmo. Et estos monasterios, con todas las cosas que sobredichas son, le damos por camio de los colazos quél á en estos rogares que aqui serán dichos..." (1305).

26 G. Martínez Díez, E. González díez, F. J. Martínez Llorente, Colección de Documentos..., o.c., pp.70-72.

27 Ibidem, pp. $113-114$

$28 \mathrm{M}^{\mathrm{a}}$. R. AYERBE, Colección documental del Archivo Municipal de Azkoitia, San Sebastián, 1993, p. 16. 
de Astigarraga: presentan como prueba un privilegio de Urbano II a Pedro I pero no exhiben la cesión de los derechos de un monarca aragonés, castellano o navarro. En este caso fue la sanción favorable a las tesis de los señores de Murguía la que legitimó finalmente los derechos de patronato ${ }^{29}$.

Es probable que la usurpación de derechos de patronazgo se hubiera generalizado antes de esa fecha pero, en Guipúzcoa, la generalización de los traspasos del patrimonio regio a los Parientes Mayores se produjo a partir de la llegada de los Trastámara y se multiplicó después de las Cortes de Guadalajara. Al menos las primeras noticias disponibles proceden del último cuarto del siglo XIV. Aunque las circunstancias que rodean cada caso son muy distintas cabe observar, sin embargo, algunas características comunes. En primer lugar, es necesario destacar los patronatos de los principales linajes de la tierra guipuzcoana como, por ejemplo, los tutelados por los Guevara tanto en Oñate como en otras iglesias del valle de Leniz después de la ya citada permuta con Fernando IV. Igualmente los de los Lazcano que ejercieron su patronazgo no sólo sobre la iglesia más cercana a su solar, San Miguel de Lazcano, sino también sobre otras del entorno inmediato como San Martín de Ataun, San Miguel de Idiazabal, San Juan de Olabarría, San Miguel de Mutiloa, Santa Fé de Campayn, en Zaldivia, y Santa María de Legazpi. A ellas, vía merced, añadieron también los derechos la iglesia de Santa María de Zumárraga cuyas "...rentas e decimas..." fueron entregadas por Enrique II en 1366 a "...Ferrant López de Lazcano, nuestro vasallo, por muchos serviçios e buenos que nos avedes fecho e nos faredes de aqui adelante...por juro de heredad para vos $e$ para vuestros herederos..." 30 . En ambos casos, Guevara y Lazcano, se trataba de un conjunto de iglesias propias que formaban el núcleo originario a las que

29 Archivo Diocesano de Pamplona, Caja 2422, n.. 1 (1422) "...prefactus dominus Joannes de Salçedo preposuit predictam ecllesiam de Murguia tanquam in territorio suo sitam et per suos antecessores fundatam vigore dicti preveligii ad suos predecessores domnos de Murguia et ad ipsos pertinisse et sperasse et per eos tanto tempore posesam fuisse quod de contrario hominum memoria no existit et sit ad ipsum et suos subcessores dominis de Murguia pertinere et spectare debere, petens iden dominus Joannes prefactum dominun Nicholaun tanquam indebitun ocupatorem ab ea removeri..."; y más adelante: "...Nos vero, viso dicto previlegio abitaque super hoc deliberacione matura, quoniam tam per depositiones testium super hoc examinatorum quam per hoc ex relactione fidedignorum nobis constitit predictam eclesiam per dominos de Murguia qui pro tempore fuerint tanto tempore fuise posesan guod de contrario hominum memoria non estitit et nichilominus eaden ecllesia in propia hereditate dicti palatii fuisse fundatam homnesque hereditates territorii de Murguia et Astigarraga fuisse ac fore propias dicti palatti et dominorum ipsius omni pro tempore fuerunt et pro nunc dicti domini Joanni de Salcedo tanquam domini de Murguia, pronunctiamus et declaramus prefactam ecllesiam parrochialem de Murguia in predicto previllegio fuisse ac fore comprehensam...". Fue pronunciada por Lancelot de Navarra, protonotario de la Sede Apostólica y administrador perpetuo del obispado de Pamplona.

30 Confirmadas más adelante en 1382 y cn 1401 . A. Duques del Infantado, Lazcano, Leg. $2, n^{\circ} 1$.

La época de Felipe Il y los Austrias

Hispania Sacra 50 (1998) 
se añadían otras de patronato real. Mayoritariamente estaban ubicadas en el mundo rural y excepcionalmente en las villas. Lo habitual era que las iglesias de éstas últimas permanecieran bajo patronato regio pero, en ocasiones, también fueron cedidas a los Parientes. Se ha citado el caso de los Oñaz y Loyola sobre el monasterio de Soreasu en Azpeitia pero también se cedió a los Iraeta la iglesia de Cestona y a los Balda el monasterio de Santa María. Igualmente los Alcega obtuvieron San Juan de Hernani, los Olaso San Andrés de Eibar y los Achega San Salvador de Usúrbil.

Pero en el mundo rural o en las villas, la estabilidad y las mercedes "por juro de heredad" no fueron precisamente la constante. El desarrollo de los acontecimientos determinó en ocasiones cambios notables en el disfrute de los derechos sobre algunas iglesias. El ejemplo de Soreasu, entregado inicialmente al de Guevara, unos años más tarde a los vecinos de Azpeitia y finalmente a Ios Oñaz y Loyola, es concluyente. Otros estuvieron más tiempo en manos de los Guevara, hasta 1367, como ocurre en el caso de la iglesia de Arriarán. En otros casos, desde finales del siglo XIV hasta 1550, se sucedieron varios patronos. Por ejemplo, Enrique III donó, apenas unos meses antes que a los Oñaz, el 7 de enero de 1394, junto al prebostazgo de Cestona “...a vos Iohan Beltran de Iraeta, mi vasallo...que tengades de mi en merced para en toda vuestra vida en quanto vos biviedes el mi monasterio de Sant Miguell de Axarnaçabal con todos tus derechos e pertenençias...". Pero, en realjdad, anteriormente, los derechos sobre esta iglesia los había disfrutado hasta su muerte Martín Sanches de Oyquina por voluntad de Juan I, sin que pueda precísarse la fecha de esta concesión ${ }^{31}$. La merced al de Iraeta fue confirmada en 1408 y seguramente a la muerte de cada Pariente Mayor del linaje hasta 1467, incorporándose, al menos desde entonces, las iglesias de San Bartolomé de Oyquina, Santa María de Aizarna y Santa Cruz de Cestona ${ }^{32}$. A la muerte del último Iraeta, Juan Beltrán, Carlos V cedió en 1531 el patronazgo sobre las iglesias a uno de los más significados elementos de la nueva élite social y política provincial: Alonso de Idiáquez ${ }^{33}$. Una movilidad, por tanto, que está estrechamente relacionada con las circunstancias sociales y políticas de cada momento y asociada a patronatos que en todos los casos son cedidos exclusivamente durante la vida del receptor. En muchos de ellos, determinados acontecimien-

\footnotetext{
31 A. Real Chancillería de Valladolid, Pleitos Civiles, Zarandona y Walls, Fenecidos, C 486/3.

32 Ibidem. La merced se renovó nuevamente "...para en toda vuestra vida..." a Juan Beltrán de Iraeta en 1485, después de la muerte de su padre.

${ }^{33}$ Archivo Histórico Provincial de Zaragoza, Hijar, Leg. $6 \pi^{\circ} 2$ (1531): "..por azer bien $e$ merçed... acatando vuestra suficiençia $e$ abilidad $e$ los muchos $e$ buenos e leales servicios que nos abeys echo e de cada dia azeys...es nuestra merced que tengades de nos por merced en cada un anno para en toda vuestra vida los monasterios e yglesias de..."
} 
tos, como la muerte del beneficiario, la favorecieron ${ }^{34}$, pero en otras ocasiones fueron los enfrentamientos entre miembros del mismo linaje $e^{35} o$ la disputa con otros competidores por los mismos derechos ${ }^{36}$, los que explican los cambios en la titularidad de los patronatos.

Junto a la creación de las iglesias o la merced real del patronato sobre las mismas, al tratarse de derechos enajenables, hubo otras formas de acceso al disfrute de los mismos. Una de ellas fue su compra. Así lo hizo García de Licona, también conocido como el doctor Ondárroa, elevado al rango de jefe del linaje después de la muerte, durante el destierro, del Pariente Mayor Ladrón de Balda $^{37}$. Igualmente, aunque la documentación no es muy explícita sobre el particular, tampoco debió ser una práctica infrecuente la compra por los linajes đe pequeñas iglesias rurales construidas por los campesinos ${ }^{38}$. En este último caso, no creo que resulte arbitrario equiparar la "adquisición" y la posible usurpación de esas iglesias por el señor de turno. Por último, la particular organización eclesiástica guipuzcoana, cuyas tierras pertenecen a tres obispados distintos - Bayona, Pamplona ${ }^{39}$ y Calahorra ${ }^{40}$-, facilitó seguramente deter-

34 Es cl caso de Martín Ruiz de San Milán, patrono de las iglesias de San Millan de Cizurquil y Santa María de Aduna que a su muerte fueron cedidas a Pedro de Idiáquez, Repostero de Cámara de los Reyes. A. Real Chancillería de Valladolid, Ejecutorias, C 178/8 (1497)

35 Es el caso de Juan López de Arriarán, o más tarde su hijo, cuyos patronatos sobre San Andrés de Ormaiztegui, San Martín de Astigarraga o San Pedro de Arriarán eran disputados por sus parientes. En A.G.S.R.G.S. 1488.V.Fol. 214.

36 Un buen ejemplo nos lo propociona el patronazgo sobre las iglesias de Santa Lucía de Galarza y San Juan de Mendiola que ostentaba Martín Sanchez de Galarza. Se lo disputaban dos mozos de ballesta del Rey que pretendían que volvieran al patronato real para que les fueran cedidos a ellos por los servicios prestados al monarca. En Archivo Duque de Sotomayor, Galarza, Leg. $1 \mathrm{n}^{\circ} 6$ (1495).

${ }^{37}$ Los Balda probablemente accedieron a los derechos sobre el monasterio de Santa María al tiempo que los Oñaz o lraeta, es decir, al final del siglo XIV. Sin embargo, la muerte de Ladrón y su hijo en Andalucía durante el destierto al que fueron enviados por Enrique IV los Parientes Mayores, truncaron las cxpectativas de mantenerlo cn su seno. El matrimonio de la hercdera con el de Licona, procedente de Lequeitio, permitio recomponer el patrimonio del linaje. En este caso fue necesario recurrir a la compra de los derechos sobre la iglesia mediante la entrega de 1.600 doblas de oro a Pedro de Silva quien disfrutaba, también por merced real, después de la muerte de los Balda, de los derechos sobre Santa María. La merced real llegó de nuevo en 1460 -A. Real Chancillería de Valladolid, Pleitos Civiles, Quevedo, Depositados, C $52 / 4$ (1509/10)- y fue confirmada más tarde en varias ocasiones. En A. Real Chancillería de Valladolid, Pleitos Civiles, Lapuerta, Olvidados, C 650/1, (1535/1544) se recoge la confirmación del patronazgo sobre Santa María de Balda a Hernando de Balda, hjjo de Juan García de Licona (7 de Marzo de 1500).

38 Este quizá pudo ser el caso del patronazgo que poseía Martín Sanchez de Galarza sobre la iglesia de San Juan de Mendiola que al parecer habria adquirido mediante el trueque de algunas caserías. A. Duque de Sotomayor, Galarza, Leg. 1, nº.(1495).

39 L. J. Fortun, "Guipúzcoa y las diócesis de Pamplona y Bayona", El Pueblo Vasco en el Renacimiento (1491-1521), Bilbao, 1994, pp. 491-501.

La época de Felipe II y los Austrias

Hispania Sacra 50 (1998) 
minadas fórmulas de acceso al disfrute de los derechos de patronazgo como el arrendamiento temporal o perpetuo de los mismos, que más tarde eran confundidos con ellos ${ }^{41}$. Tampoco debió resultar extraordinario la cesión o traspaso del patronato sobre las iglesias entre los hidalgos guipuzcoanos o entre un Pariente Mayor y un miembro de su clientela ${ }^{42}$. En conjunto, las distintas fórmulas de acceso a los derechos de patronazgo diseñaron un mapa de iglesias de patronato laico en el territorio guipuzcoano que integraba buena parte de las iglesias del centro y del sur y tanto las ubicadas en el mundo rural y de las villas, especialmente si éstas últimas habían sido fundadas durante el siglo XIV. No creo equivocarme al afirmar que la mayoría de las iglesias estaban bajo el patronazgo de los Parientes Mayores o de otros linajes hidalgos de menor rango. Una situación muy similar a la vizcaína ${ }^{43}$.

\section{LAS RENTAS DERIVADAS DE LOS DERECHOS DE PATRONAZGO.}

Los diezmos, primicias y ofrendas entregados por los parroquianos de cada una de las iglesias, así como los procedentes de los bienes asociados a las mismas, se constituyeron en una fuente segura y saneada de ingresos para las arcas de los Parientes Mayores o de los hidalgos rurales. Adviértase, además, la importancia creciente de estos ingresos durante un periodo de contrastado crecimiento de la producción agrícola y especialmente durante los siglos XV y XVI que, a su vez, pueden explicar la disputa entre los Parientes o entre los miembros del mismo linaje en torno a la percepción de esas rentas. Parece oportuno, en consecuencia, definir las rentas más allá de su denominación, concretar cuando sea posible su valor, analizar su gestión y resaltar todos

40 J.L. MANERo, "Relaciones entre la diócesis de Calahorra y el Pafs Vasco a fines de la Edad Media y comienzos de la Moderna según la documentación conservada en el Archivo Catedral Calagurritano", El Pueblo Vasco en el Renacimiento (I491-J52I), Bilbao, 1994, pp. 501-522,

41 Este es el caso del contrato firmado en 1404 entre el Chantre de la Catedral de Pamplona y Oger de Amézqueta, sextor de Lazcano, por el que este último se comprometía a pagar en Pamplona, cada Navidad, 20 florines de oro. Oger de Amézqueta se aseguraba a cambio nombrar al cura de la la iglesia parroquial de Zaldivia dedicada a Santa Fé de Campayn. Durante los años veinte del siglo XVI, Felipe de Lazcano se reclamará patrón de la misma. A. Diocesano de Pamplona, Ollacarizqueta, C 75, $\mathbf{n}^{\circ} 22$.

${ }^{42}$ Así ocurre en el caso de la cesión solicitada por Belttán de Guevara en 1452 a favor de Fortún García de Elgueta. $M^{2}$ R. AYERBE, Historia del Condado..., I, p. 120: "...si a Vuestra Alteza pluguyese, yo querría renunçiar y traslasar, e por la presente renunçio e trespaso el dicho monasterio de Anguyoçar e patronazgo del con todo lo sobre dicho a Fortún Garçia de Elgueta, fixo de Garçía Ybánes d'Elgeta, por muchos e buenos servicios que me ha fecho y por grand cargo que del tengo...". La hizo "...con todos los diezmos e rentas de la parroquya del dicho monasterio, fueros e derechos, $e$ con todas las otras cosas al dicho monasterio y en la su perrochia perteneçientes, con el patronazgo del dicho Monesterio..."

${ }^{43}$ E. CATALÁN, “ La pervivencia...”, o. c., pp. 567 y ss. 
aquellos aspectos más cualitativos que permiten poner en valor otras variables asociadas al disfrute de los derechos de patronato: nombramiento de los clérigos, preeminencia en la iglesia y en la ubicación de los lugares de enterramiento, etc. Nada mejor para ello que hacerlo a través de la opinión de un Pariente Mayor en los primeros años del siglo XVI cuando se sentía amenazado por la creciente intervención del concejo sobre sus intereses más inmediatos. Se trata del escrito que Martín García de Oñaz remitió en 1507 al concejo para que le fueran reconocidos por este sus derechos sobre Soreasu. Detalló entonces qué suponía el disfrute del patronato ${ }^{44}$. El estudioso de este linaje lo ha concretado de un modo brillante: "nominar e investir a los clérigos, disfrutar de las rentas decimales, el derecho a intitularse patrón, el privilegio de que el concejo observara tal condición y que fuera transmitido al heredero y que, finalmente, se le respetara "...en todos los otros usos preheminençias libertades $e$ honras..." al igual que a sus antepasados ${ }^{45}$. La coyuntura de la redacción del texto pesa sobre el mismo, 'pero ayuda a explicar también el porqué de la detallada descripción de unos derechos cuyo reconocimiento se reclama a quien puede hacerlo.

Me ocuparé en primer lugar del disfrute de las rentas decimales. ¿En qué consistían estas?. Nada mejor para responder a esta pregunta que acudir a otra incluida en el interrogatorio realizado a los vecinos de Zumárraga con motivo del pleito que mantenían con Bernaldino de Lazcano en 1488: "...Sean preguntados cuanto puede valer e rendar el diezmo que los vecinos de la dicha tierra de Zumárraga estan tenidos de dezmar...el trigo e boron e çebada e avena e otras sementeras e manzana e castannas e nuezes que por los veçinos de la dicha tierra se coge e de los ganados mayores e menores de toda ralea $e$

\footnotetext{
44 J.A. MARÍN, "Semejante Pariente Mayor"..., o.c., pp. 328-329: “... e presentaron solos syn otra compannya, los rectores e benefiçiados bacantes de la dieha yglesia, cada e quando bacaron las dichas rectorias $e$ benefiçios. $E$ asy mesmo estubieron $e$ han estado $e$ estan en la posesyon, Beltran Ybanes, de llebar e coger e conberter en sus propios usos todas las deçimas del dicho monasterio $e$ Yglesia, salvo las anexas a la dicha receoria e benefiçios que son el quarto déllas e las dichas posesyones, Beltran Ybannes, tubieron $e$ han tenydo los dichos Beltrán Ybannes $e$ su.sucesores e tados $e$ cada uno dellos segund todos los dichos sus tiempos de uno, dos, cinco diez, vcynte e cinquenta $e$ ciento e dosientos anos e mas tiempo a esta parte atynadamente e de tanto tiempo aca que memoria de omes no es en contrario por justos e dereehos rytulos que para ello los dichos Beltran Ybanes $e$ sus mayores $e$ anteecesores han tenydo de los reyes de Castilla e de Lcón de gloriosas e ensalcadas memorias aquí mesmo los muy alto.e serenysimos ensalçados prínçipes, el rey Don Ferrando e la reyna Doña Ysabel de la muy alta ensalcada e gloriosa memoria que Santa Gloria posean probetyeron al dicho Beltran Ybannes $e$ a sus postreros progenitores $e$ suboçesores hercderos unybersales $e$ los titularon segund e de la manera e como $e$ de lo que en la dicha su provision real que presentada tenya parescian..."

45 Ibidem, p.329.
}

La ćpoca de Felipe II y los Austrias

Hispania Sacra 50 (1998) 
suerte..." 46. En otros casos se expresaba de otro modo: "...pan, mijo, e sydra $e$ ganados e linos..."47. En todo caso diezmaban todos y por cada uno de los productos agropecuarios. Pero, bajo la denominación de "déçimas", se incluyen no solo los ingresos procedentes de los diezmos propiamente dichos, sino también las primicias y las ofrendas, también denominadas "...oblaciones e pie de altar..." 48 .

El reparto y la gestión de cada una de estas fuentes de ingreso era distinto según los casos y las circunstancias. Lo habitual era que el patrón percibiera los diezmos en una proporción variable entre la mitad y los tres cuartos. El resto quedaba para los clérigos que atendían el culto, los cuales, además, se reservaban usualmente entre la mitad y los tres cuartos de las ofrendas o pie de altar. La gestión de cada uno de estos apartados era distinta no sólo según los perceptores sino también según la costumbre de arrendar conjuntamente o no los diversos productos con las rentas procedentes de las tierras de la iglesia de turno, conformando un complicado entramado de situaciones que a menudo necesitarían un tratamiento diferenciado caso por caso. Ciertos ejemplos, sin embargo, muestran algunas tendencias que pueden iluminar distintos procedimientos seguidos por los patronos para gestionarlos. Así, el de Guevara, arrendaba globalmente las rentas del monasterio de San Miguel de Oñate “...con todas sus décimas, e pies de altar, e obladas anuales, e ruedas, e molinos, $e$ medios plantios, e rentas, e derechos, e pertenençias que al dicho sennor perteneçen, commo a sennor $e$ poseedor del dicho Monesterio $e$ sus pertenençias..." 49 . Unos años antes, sin embargo, también por un espacio de seis años, había arrendado solamente la mitad de las rentas de Santa Marina de (1488)

46 A. Real Chancillería de Valladolid, Zarandona y Watls, Pleitos Civiles, Olvidados, C 1320/1

47 A. Real Chancillería de Valladolid, Ejecutorias, C 99/5 (1496).

48 C. DALMASES, Fontes..., o.c., p.130

${ }^{49} \mathrm{M}^{\mathrm{s}} \mathrm{R}$. AYerBe, Historia del Condado..., o.c., pp. 157 a 160 (1467). Lo arrendó a "...Rodrigo Yvánes d'Olabe, veçino otrosy del dicho Condado, que presente estava..." especificando que el arrendamiento incluia "...todo lo que se acostunbra andar con la renta del dicho Monesterio e los arrendadores que han seydo d'él acostunbran coger e recabdar, asy en el dicho Condado commo fuera d'él: e con la casa de lagar, e bodega, e cubas del dicho Monesterio, e segúnt e de la guisa e manera que el dicho sennor lo dió en renta a Juan Yvánes de Laçarraga, e a Juan Miguéles de Araos por los seys anuos que se cunplieron por el dia de Sant Juan de Junio d'este dicho anno, e en las condeçiones ende mençionadas e declaradas. El qual dicho Monesterio e pertenençias segunt e de la guisa que es dicha, dió el dicho Pero Lópes al dicho Radrigo Yvánes para que pueda coger, recabdar, aver e cobrar para sy todo ello en seys annnos cunplidos primeros seguientes, començando los dichos anuos por el día de Sant Juan de Junio postrimero pasado, e obligó a los bienes del dicho sennor a lo faser valer la dicha renta de guisa que la pueda coger libremente redrandole d'ella toda mala bos, so pena del doblo...". Por ese mismo tiempo arrendaba sus diezmos también el de Olaso sobre la iglesia de San Bartolome A. R. Chancillería de Valladolid, Ejecutorias, C 15/29 (1488). 
Oxirondo y San Juan de Uxarraga ${ }^{50}$. El de Balda, sin embargo, patrón únicamente de la Iglesia de Santa María, en Azcoitia, arrendaba por un lado los diezmos del trigo y por otro la primicia ${ }^{51}$. El arrendamiento, incluso, se refirió en ocasiones a una parte de las casas que diezmaban a la iglesia de turno, como ocurría en Cestona, donde "...la casa de Yraeta...solia coger e llevar todo el diesmo e frutos e rentas de la parte aquende el rio..."

En todo caso, la gestión, entendiéndola no sólo desde el punto de vista del itinerario seguido en cada caso para la percepción de las rentas, sino también desde la administración y gasto de las mismas, está estrechamente relacionada con los intereses y problemas concretos que en cada caso y en cada momento afectan a los distintos patronos que, obviamente, consideran estos ingresos y problemas como una pieza más de su engranaje patrimonial. En el marco de una gestión integral de su patrimonio y al ser los derechos de patronato enajenables, no resulta extraño que los diezmos, ofrendas y el conjunto de rentas correspondientes al patronazgó sobre una iglesia fueran objeto de venta, como ocurre con los derechos sobre las iglesias de Oxirondo, Usarraga y Elgueta que fueron vendidas en 1518, por el Guevara de turno, a Lope García de Salazar ${ }^{53}$; que los derechos sobre Santa María de Balda fueran utilizados por Martín García de Licona para pagar la deuda correspondiente al préstamo que le había hecho el sefíor de Olaso, Martín Ruiz de Gamboa, precisamente para recuperar mediante compra para el linaje de Balda la propia iglesia de Santa María ${ }^{54}$;

so Ma R. AYERBE, Historia del Condado..., o.c., pp. 143-147: "... Otorgamos e conosçemos que devemos dar e pagar a la sennora Donna Costança la de Ayala e a vos, Rodrigo de Cuesta, su procurador en su nonbre, o a qualquier otra persona que su poder tobiere para ello, dosientas e setenta y seys mill marabedís de la moneda corriente en Castilla, que de dos blanca biejas o de tres nuebas fasen un marabedi, $e$ más syete capones. Los quales...nos ovemos a dar e pagar a la dicha sennora Donna Costança por la meytad de las rentas que nosotros tomamos e arrendamos de lo que pertenesçe a las Yglesias e Monesterios de Santa Marina de Oxirondo e San Juan de Uçarraga, asy de la meytad de los diesmos de las dichas Yglesias commo de las ruedas, e prados, e pastos, e mançanales $e$ otros qualesquier árboles, e frutos, e rentas, e heredamientos que a las dichas Yglesias e Monesterios, segúnd suelen andar en renta en los anuos pasados. Los quales dichos dosientas e setenta $e$ seys mill marabedis, e más siete capones, vos ovemos a dar e pagar en seys anuos que ovemos de tener la dicha renta, en la forma seguiente: el día de Pascoa de Resurreçión que será en el anno del Sennor de mill e quatrocientos e sesenta anuos, los veynte e tres mili marabedís, que son en anbos plasos quarenta e seys mili marabedis que viene e pertenesçe a pagar a nosotros en cada anno por los dichos seys anuos que tura la renta...".

$\$ 1$ A. Real Chancillería de Valladolid, Pleitos Civiles, A. Rodriguez, Fenecidos, C 1334/2 (15071509).

52 A. Real Chancilleria de Valladolid, Pleitos Civiles, Zarandona y Walls, Olvidados, C 1334/2 (1486).

$53 \mathrm{M}^{\mathrm{a}} \mathrm{R}$, AYERBE, Historia del Condado..., o.c., I, p. 561.

54 A. Real Chancillería de Valladolid, Pleitos Civiles, Zarandona y Walls, Olvidados, C 934/8 (1486-1489).

La época de Felipe II y los Austrias

Hispania Sacra 50 (1998) 
que, por último, determinados bienes asociados a Soreasu, concretamente dos seles, fueran vendidos por el patrón ${ }^{55}$.

Por otra parte, la administración de los ingresos derivados de los derechos de patronato colocaba a los titulares de los mismos ante los vaivenes de la producción y de los precios, como les ocurre en alguna ocasión a los Balda ${ }^{56}$. Sin embargo, considerada la cuestión durante el periodo de estudio, la producción se incrementó considerablemente y los precios, en particular los del trigo, experimentaron un crecimiento notable lo cual colaboró a multiplicar los ingresos de los Parientes Mayores que disfrutaban de derechos de patronato y percibían sus rentas en especie. Además, en todo caso, su posición era siempre inmejorable y sobre todo en épocas de escasez ya que, en esos momentos, mientras se disparaban los precios del trigo, una parte del escaso grano circulante permanecía en sus manos ${ }^{57}$.

Pero además de identificar los distintos conceptos que están bajo la denominación de las rentas decimales de los monasterios y observar, a través de los numerosos pleitos, el interés de patronos y parroquianos por los ingresos derivados de esos derechos ¿cabe avanzar algo más en el conocimiento del valor de esas rentas?, ¿es posible concretar su valor en el contexto de los ingresos que en cada caso nutren las arcas de los Parientes Mayores?. La empresa resulta difícil, por no decir imposible. En realidad la información disponible comunica solo puntual y excepcionalmente el valor de los diezmos correspondientes a cada una de las iglesias bajo patronato de los Parientes. En todos los casos se trata siempre de estimaciones o de cantidades que se corresponden con el arrendamiento de las rentas asociadas al patronato lo cual tiene graves limitaciones para el análisis como las anteriormente señaladas ${ }^{58}$. Así, por ejem-

55 L. FERnÁNDEZ, "Los sefiores de la Casa de Loyola, patronos de la Iglesia de San Sebastián de Soreasu", BRSBAP, año XLII, 1986, p. 509.

56 A. Real Chancillería de Valladolid, Pleitos Civiles, Zarandona y Walls, Olvidados, C $1334 / 2$ (1486).

57 Ibidem. El procurador de un arrendador de los diezmos en trigo del monasterio de Santa María de Balda, se quejaba en la Chancitlería, de que en un año de escasez había perdido una cantidad importante de fanegas y que, además, el señor de Bajda “...no quiso enbiar a resçibir nin cobrar el dicho pan el dia puesto al dicho mi parte e se lo dexo en su poder con la intençion que agora ha mostrado quel prescio del dicho pan suberia e que ge lo demandaria junto alos mayores presçios..."

58 Ibidem, Pleitos Civiles, Moreno, Fenecidos, C 1432/2 (1494).Los datos reflejan también la compartimentación de los ingresos y la dificultad de realizar incluso valoraciones sobre el terreno en los momentos de enfrentamiento entre las partes. Así la Sen̈ora de Yarza y los representantes de la "...tierra de Beasain dixeron que tan solamente la renta e diezmos que de consuno a medias llieban el dicho don Juan e la dicha Sennora...syn la renta e diezmos que de suso van espeçificadas e declaradas de que la renta e diesmos della lileba el dicho don Juan enteramente para sy que lo al vale y monta un anno con otro treynta mill mrs. poco mas o menos y asy bien el pie de altar que asy mismo lieva el dicho don Juan syn parte de la dicha sennora ...que vale e monta seys mill mrs. poco mas o 
plo, en el pleito que enfrenta a Zumárraga con el de Lazcano, uno delos testigos afirma "...que oyó dezir que rinde un anno con otro mill e dozientas fanegas que montan 60.000 mrs...." 59. Sin embargo, en 1527, Bernaldino de Lazcano, arrendaba los diezmos de Santa María por $20.000 \mathrm{mrs}$. al año ${ }^{60}$. Sabemos también que, en el caso del monasterio de San Miguel de Oñate, a fines del $\mathrm{XV}$, los ingresos que percibía el conde se situaban en torno a los 100.000 $\mathrm{mrs}^{6 !}$. En el caso de la iglesia de San Andrés de Eibar, el señor de Olaso fijaba cada año su renta en 21.500 mrs. ${ }^{62}$.

Del mismo modo, gracias al préstamo que el señor de Olaso realizó para comprar Santa María de Balda, sabemos que "...el dicho Martin Ruys...llebo e fizo llebar la mitad de la renta e rentas de dicho monasterio de Santa María de Balda por espaçio de siete annos poco mas o menos tiempo deziendo que los llevaba e fazia llebar para en pago de las dichas doblas e quantia que dio al dicho Pedro de Silva...e que sabe que en cada un anno podia rendar lo que asy el dicho Martin Ruys llevaba setenta e cinco mill mrs. poco mas o menos $\ldots$... 63, es decir, en torno a $150.000 \mathrm{mrs}$. anuales ${ }^{64}$. Unos veinte años más tarde, Juan de Larrume, vecino de Azcoitia y arrendador de los diezmos de Santa María, hizo saber que "...el anno de quinientos e siete pasado tube cargo, por el dicho Fernando de Valda e por Juan Garçia de Valda su padre, de coger

menos e la renta e diezmos que el dicho don Juan asy lieva de las dichas casas para sy propiamente non estimaron porque non se pudieron ygualar..."

59 Ibidem, Pleitos Civiles, Zarandona y Walls, Olvidados, 1320/1 (1487). Otro de los testigos no dudaba en afirmar que "...nunca ha cogido el diezmo e primiçia de la dicha yglesia mas acatando e mirando por lo que se arrienda la primiçia un anno con otro por treszientos florines corrientes por tal manera que se ha de pagar de diez uno a este respecto puede valer e vale $60.000 \mathrm{mrs}$. dos mill mrs.mas dos mill mrs. menos...". La ejecutoria recogió estas informaciones dándolas por buenas:"... visto como el dicho diezmo de la dicha yglesia de Santa Maria de Zumarraga puede rentar en cada un anno sesenta mill mrs...".

60 A. Duques del Infantado, Lazcano, Leg. $11 \mathrm{n}^{\circ} 27$.

$61 \mathrm{M}^{\mathrm{a}}$ R. AYERBE, Historia del Condado ..... I, o.c., pp. 543 y 544. Las rentas de Oxirondo y Usarraga, conjuntamente, llegaron a montar unos $200.000 \mathrm{mrs}$. a juicio de tres personas que fucron elegidas para evaluar lo que se habían quedado los clérigos Ibidem, p. 561.

62 A. R. Chancillería de Valladolid, Pleitos Civiles, A. Rodríguez, Fenecidos, C 1625/1 (1506)."... en que dandome e acudiéndome a mi $e$ a los patronos que subçedieren en el dicho patronazgo en cada anno 21.500 mrs. de moneda buena castellana que todo el resto de las dichas deçimas aya de ser anexo a los dichos dos benefiçios..."

63 Ibidem, Pleitos Civiles, Zarandona y Walls, Olvidados, C 934/8 (1486-1489).

64 En la Ejecutoria de 1484 en la que se dictó sentencia sobre la elección de los clérigos, el procurador del concejo ratificaba el valor de los ingresos del patronato cuando contestaba a las demnadas del patrón del siguiente modo: "E que el dicho Juan Garçia non se deviere quexar que de çiento $e$ sesenta mill mrs. e mas que valia la renta de la dicha iglesia que para el serviçio della oviese de dar treinta e dos mill mrs..." $\mathrm{M}^{\natural}$ R. AYERBE, Documentación medieval del Archivo Municipal de Azkoitia, o.c., doc. $n^{\circ} 51$, p. 153 .

La época de Felipe II y los Austrias

Hispania Sacra 50 (1998) 
los diezmos de la yglesia de Santa María de Valda conque yo les diese por los dichos diezmos a los susodichos quinientas e ochenta e tres fanegas y media de trigo, a cada uno de los susodichos la meytad..."65. Estas dos últimas noticias, pudieran haber iluminado, pese a las limitaciones señaladas, algunos aspectos de interés al ser cronológicamente distantes. Resulta muy arriesgado, sin embargo, compararlas porque la primera, por las circunstancias en que se produce la cesión al đe Olaso, incluía probablemente todas la rentas del monasterio; la segunda, en tomo a $70.000 \mathrm{mrs} .{ }^{66}$, sin embargo, es seguro se refiere solo al diezmo del trigo y en un año de escasa producción y altos precios.

Por otra parte, se conoce gracias a las informaciones procedentes del pleito entre Martín Ruiz de Gamboa, señor de Olaso, y Juan García de Licona, señor de Balda, con motivo del incumplimiento del contrato matrimonial realizado entre ambos linajes, una estimación más o menos grosera, del patrimonio y las rentas de ambos en los años ochenta del siglo XV. Así, una de las preguntas del interrogatorio planteaba a los testigos "...si saben que el dicho solar e palaçio de Olaso...rendia e podia rendir en cada un anno mill e seysçientos florines de oro e mas en monasterios e patrimonios e otras pertenençias e bienes a el pertenesçientes...", mientras que su patrimonio se valoraba en 20.000 florines de oro $^{67}$. Respecto a los Balda, los testigos no ofrecen la valoración patrimonial de sus bienes, pero reiteran que "...el dicho solar e palaçio de Balda...rendia e puede rendir en cada un anno mil florines de oro de la ley $e$ cunno de Aragon...", destacando algunos de ellos que "...que la casa e solar de Valda es una de las arrentosas casas de la provinçia de guipuscoa, e bien cree que su renta es mill florines de oro poco mas o menos, e...este testigo, syn cargo de conçiençia, puede dezir que vale a lo menos dozientos mill mrs. $e$ aun mas, e que esto sabe porque en algunos tiempos este testigo ha tenido en renta algunas rentas de la dicha casa..." 68 .

Los datos son parcos pero a mi parecer pueden aproximarnos al porcentaje que representaban en el caso de los Balda los derechos de patronato. Con todas

65 bidem, Pleitos Civiles, A. Rodriguez, Fenecidos, C 1334/2, (1507-1508).

${ }^{6}$ El precio del trigo en 1507 rondaba los $120 \mathrm{mrs}$. He tomado los precios del trigo de Vitoria porque, como es sabido, cran referencia habitual en los mercados de las villas guipuzcoanas. L. $\mathbf{M}^{\text {a }}$ BILBAO, "El precio de los cercales en la ciudad de Vitoria durante el siglo XV (1433-1513)", en Vitoria en la Edad Media, Vitoria, 1982, pp. 393-406.

${ }^{67}$ Ibidem, Zarandona y Walls, Pleitos Civiles, Olvidados, C 934/8 (1486-1489): “..fallesçio de la presente vida...Martin Ruis de Olaso... fiso $e$ ordeno su testamento e postrimera voluntad...e el dicho Juan Lopes su fijo entro e tomo todos sus bienes patrimoniales e monesterios e caserias $e$ molinos e ferrerias e montes e tierras $e$ heredades $e$ ganados e fierros...e otros muchos bienes que podian valer e balian los dichos bienes...de mas e alliende de los dichos monesterios veynte mill florines de oro de la ley e cunno de Aragón..."

68 lbidem. 
las reservas y limitaciones de una afirmación de estas características, es evidente que las rentas de Santa María representaban sobre el total un altísimo porcentaje: según los datos disponibles en torno a un $75 \%$ del total de los ingresos de los Balda. Extrapolar este dato al resto de los derechos de patronazgo percibidos por los Parientes Mayores puede resultar seguramente exagerado, entre otras razones porque, todo parece indicar, que en el caso de Balda, la renta de Santa María es la más importante que conservó el linaje después de la muerte en el destierro del Pariente Mayor y su hijo. En general, por tanto, una mayor diversificación de los ingresos y de modo especial, por ejemplo, la presencia de rentas procedentes del sector secundario, como parece ocurrir en el ya citado ejemplo de Olaso, modificarían sensiblemente a la baja el porcentaje de referencia. Con todo, tampoco parece prudente minusvalorar los ingresos procedentes de esos derechos. Además, no solo el linaje de Balda recibió mayoritariamente sus rentas del patronato de las iglesias. Probablemente los Iraeta de Cestona, que disfrutaban de las rentas de un número significativo de iglesias, se acercaron seguramente a ese elevado porcentaje, completándolo con las rentas derivadas del oficio de preboste de esa villa y quizá, como parecen corroborarlo datos de la segunda mitad del siglo XVI, lo mismo sucedió en el caso de los Oñaz y Loyola ${ }^{69}$.

Pero como se ha señalado, las rentas en especie o en metálico procedentes de las iglesias de patronato no eran los únicos derechos de los que disfrutaba el titular. Aún más, en muchos casos tan siquiera eran consideradas por este como lo más importante, especialmente cuando se trataba de pequeños lugares. Había otros elementos que demostraban el poder del patrón frente al resto de la comunidad. En primer lugar, tenía el derecho de presentación de los curas, es decir, nombraba a los clérigos ${ }^{70}$. E. Catalán ha resumido con precisión el signi-

${ }_{69}$ En un Memorial elaborado en 1569 por Francisco Pérez de Yarza por encargo de los Loyola se seffiala lo siguiente acerca de las rentas del linaje: "En respuesta del quatro capitulo hazerca de la renta que tiene la casa de Loyola, assid de patronazgo como de hazienda etc. digo que como esta dicho en primer capitulo de este memorial el patronazgo que la dicha casa tiene en esta dicha villa de Azpeitia le vale mil ducados poco mas o menos...y demás dello, valdrá la rayz todo seteçientos ducados cada año...". C. DALMASES, Fontes..., o.c., pp, 740 y 741 . La "rayz" incuye veintiún caserías, un molino, una herrería, dieciséis seles. Tenían además otras casas y solares de casas en el interior de la villa no incluídas entre los bienes raíces anteriores. Con todo, el porcentaje de las rentas de los Loyola procedente del patronato sobre San Sebastián de Soreasu superaba o rondaba el 50\% de las que percibia en Azpeitia.

${ }_{70} \mathrm{M}^{*} \mathrm{R}$. AYERBE, Historia del Condado..., $/ I$, o.c., p.87. 1419 Mayo 5 (s.l.). Nombramiento de abad del monasterio de S Miguel de Onate hecho por Pedro Vélez en la persona đe Pedro Ibáñez de Guevara, su "natural", mandado al monasterio que le reconociesen por tal." Curas e clérigos y Cabildo del mi Monesterio de San Miguel de Hoñate. Yo, Don Pedro de Guebara, señor de Hoñate, bos enbio mucho a saludar como aquellos para quien yo querría que Dios diese mucha honrra y mucho bien. Fágobos saber que yo, como señor e patrón mayor del dicho mi Monasterio de San Miguel, es 
ficado de este derecho: "el privilegio económico que emanaba del patronato se perpetuaba a través de la designación personal del clérigo que debía servir10"71. El clérigo era un pieza central que sostenía el "edificio espiritual" en el que se apoyaban los derechos económicos derivados del patronato. Sin embargo su dependencia del patrono tanto en su nombramiento como en los ingresos que percibía por el desempeño de su función era absoluta de modo que se elegía a los clérigos que mejor se adecuaban a los intereses del patrón tanto desde el punto de vista religioso, como económico, eligiéndose a aquellos que aceptaban la renta acordada inicialmente o a aquellos de su linaje que cumplian el papel de alter ego en el interior de la iglesia. En todo caso, insuficientemente formados - "...en la dicha villa se fazen muchos clerigos que non eran gramaticos nin avian estudiado en estudio alguno..."-, escasamente pagados _.."...por que los dichos clerigos de la dicha iglesia tienen poca renta..." 72 - y en ocasiones mal considerados por sus parroquianos, desarrollan su trabajo en condiciones poco adecuadas a la función espiritual que tenían encomendada ${ }^{73}$ porque el patrón restringía al máximo el número de clérigos de las iglesias, de modo que son habituales las quejas de los parroquianos ${ }^{74}$.

La ocupación de un lugar preeminente en la iglesia, tanto durante la misa y otros actos litúrgicos como después de la muerte, es otro de los elementos

mi merçed y boluntad de poner e pongo por Abbad del dicho mi Monesterio, a Don Pedro Ybáñes de Guebara, mi natural. Porque bos mando a todos e cada uno de bos, que lo ayades e reçibades al dicho Don Pedro Ybánes por vuestro Abad, de aqui adelante, y lo honrrades y hobedezcádes sus mandamientos, según que por mi está hordenado, por quanto represente mi persona y, en el dicho mi Monasterio. $\gamma$ que qualquier o qualesquier personas que no hobedesçiere y cunpliere sus mandamientos e fuere rebelde, es mi merçed que pase ho pasen por las pena ho penas que por mí está de ante hordenada y puesta. $Y$ porque esto es bardad, di esfa carta abierta, firmada de mi nombre, sellada con mi sello, a çinco días de Mayo, año del nasçimiento del Nuestro Señor Jesu Christo, de mili y quatroçientos y diez y nuebe años. Pedro".

71 "La pervivencia del derecho patrimonial...", o.c., p. 583.

72 C. DAlmaSES, Fontes..., o.c., p.180. Se trata de unas ordenanzas sobre los nuevos clérigos de la villa de Azpeitia.

${ }^{73}$ Sobre el papel de los clérigos, su fornación, etc... véanse los siguientes trabajos: G. LOUBÈs, "Le clergć nural Gascon à la fin du Moyen Âge (XIVe-XVIe siècles), y R.N. SWANSON, "Le clergè rural anglais au bas Moyen Âge (vers 1300-vers 1530)", en Le clergè rural dans l'Europe médiévale et moderne, P. Bonnassie/Ed., Toulouse, 1995, pp. 41 a 59 y 60 a 100 respectivamente. También los trabajos de I. del VAl VAlDivieso, "El clero vasco a fines de la Edad Media", en Cuadernos de Sección Historia-Geografia, 23 (1995), pp. 31 a 53; J.R.MURO ABAD, "El clero diocesano vasco en los siglos XV y XVI: una imágen" y E. GARCíA FERNÁNDEZ, "Catecismos y catequesis cristiana en las comunidades vascas (siglos XIV a XVI), ambos en Religiosidad y Sociedad en el Pais Vasco (siglos XIV $a X V I$ ), Emesto García Fernández (director), Bilbao, 1994, pp. 53 a 82 y 25 a 51 respectivanente.

74 A. Duques del Infantado, Lazcano, Leg. 11 n 11 (1486). En Zumáraga, por cjemplo, “...la dicha universidad e feligreses $e$ vezindad han padeçido $e$ padeçen mucha mengua de clerigos $e$ sacerdotes e que a esta causa muchas personas son falleçidas syn les oyr a penitençia nin les administrar los sacramentos...". 
centrales en el disfrute de los derechos de patronazgo. La permanente escenificación de este derecho era considerado por el patrón y los vecinos como el símbolo de la ostentación del patronazgo. Baste el ejemplo del señor de Iraeta, preboste de Cestona, para comprobar hasta que punto, fuera y dentro de la iglesia, el dominio sobre los hombres no era solo una representación. El de Iraeta no solo -"...solia ante que otro ninguno antiçiparse $e$ anteponerse a todos los otros legos que ende llegasen como principal persona..."-, sino que disponía también la ubicación de los parroquianos en los bancos de la iglesia ${ }^{75}$. Los escasos episodios violentos que se produjeron durante los enfrentamientos en torno a los derechos de patronato de los Parientes Mayores, tuvieron precisamente como protagonistas al lugar preferente que ocupaban los señores en la iglesia y a las tumbas en las que enterraban a sus antepasados ${ }^{76}$.

\section{DESAFIANDO "EL LADRIDO DEL GRAN CAN" LOS PARIENTES MAYORES Y LOS PARROQUIANOS EN TORNO A LOS DERECHOS DE PATRONAZGO.}

El enfrentamiento entre patronos y parroquianos en torno a los derechos de patronazgo de las iglesias tiene lugar durante todo el periodo de estudio. Sin embargo es sobre todo entre 1480 y 1510 cuando se generaliza adoptando en ocasiones caracteres de un auténtico levantamiento antiseñorial ${ }^{78}$. En cada caso la causa inmediata de la disputa entre ambos fue diferente y estaba estrechamente relacionada con las circunstancias que rodeaban el ejercicio de los derechos de patronazgo. Los más habituales tienen lugar por el número de clérigos que debía servir el culto en la iglesia de tumo, por el nombramiento del cura,

75 A. Real Chancillería de Valladolid, Pleitos Civiles, Zarandona y Walls, Olvidados, C 88/6, (1486). Como recordaba un testigo, “...quando los parroquianos o algunos dellos ovieren diferenç̧ia sobre los asientos de la dicha yglesia que solyan pasar por lo que el dicho Fortun Sanches les mostrase e que el solia mandarles a cada uno donde era el suyo...".

76 Es bien conocido, gracias a Alfonso de Otazu, el caso del señor de Berastegui que en 1553 se querello contra unos vecinos porque estos de noche, escalando la iglesia, le quebraron la tumba y juntándose con mucha gente con arnas avian derribado cl asiento y todo lo habían sacado de la iglesia. El "igualitarismo...", o.c., p. 83.

77 A. Real Chancillería de Valladolid, Pleitos Civiles, Zarandona y Walls, Olvidados, C 88/6, (1486). Uno de los testigos en el pleito entre Iraeta y los parroquianos se refería de este modo a las represalias que cabía esperar del poderso a quien se estaban enfrentando: "...non queria aver question con la casa de Yraeta e que con lo poco que tenia se queria pasar, que el gran can solia dar gran ladrido...".

78 P. FERNÁNDEZ ALBADALEJO señala que los conflictos, aunque se iniciaron el s. XV, alcanzaron su punto álgido durante el siglo XVI y que, "en principio la batalla se centró sobre los símbolos del patronazgo". La destrucción de este simbolo señorial formaba parte de una ofensiva destinada a borrar el pasado feudal de la Provincia. En La crisis del Antiguo Régimen en Guipúzcoa (1766-1833). Cambio económico e historia. Madrid, 1975, pp. 111 a 120.

La época de Felipe II y los Austrias

Hispania Sacra 50 (1998) 
por el disfrute de las rentas procedentes de los diezmos y de los bienes asociados al monasterio así como por el reconocimiento del derecho de patronazgo.

No pretendo ser exhaustivo en cuanto a la tipología de los conflictos. Es habitual, sin embargo, que la iniciativa corra a cargo de los parroquianos que demandan el incremento del número de clérigos dedicados a servir los oficios religiosos para la comunidad y que éstos cuenten con los recursos económicos y culturales necesarios para hacerlo con dignidad. Adviértase que cuando esto sucede, en buena parte de los casos, los parroquianos coinciden con los vecinos del concejo, de modo que no resulta difícil percibir detrás de las demandas concretas un notable interés por recuperar los derechos de patronato sobre la iglesia. La iniciativa, además, suele coincidir con momentos de cierta debilidad para el titular. Así ocurre, por ejemplo, en Zumárraga donde los vecinos se enfrentan al patrón de la iglesia de Santa María, Bernaldino de Lazcano, unos años más tarde de la muerte de su padre en la torre de Contrasta. Su argumentación giraba en tomo a una queja reiterada en otras ocasiones por otros parroquianos: el crecimiento del vecindario - "...diz que puede aver mill e seteçientas personas ..."- - no era correspondido por el patrón con un incremento paralelo del número de clérigos. En este caso, únicamente "...han puesto en ella un clerigo e aquel no habil ni ydoneo ni sufiçiente $e$ sin autoridad de perlado alguno por manera que la dicha universidad e feligreses han padeçido e padeçen mucha mengoa de clerigos e sacerdotes e que a esta causa muchas personas son fallesçidas syn les oyr a penitençia nin les administrar los sacramentos...". Nótese, sin embargo, que los vecinos de Zumárraga acudieron a la reina Isabel no como parroquianos sino como vecinos y en su condición de tal se quejaban de que "...los señores de la casa de Lazcano non saben por que titulo tienen tomada e ocupada la dicha yglesia e monesterio e han llevado e llevan los frutos e rentas e prebendas della..." ${ }^{79}$. Del mismo modo, en Hernani, el concejo acusó en 1490 a Juan López de Amézqueta, señor de Amézqueta, Alcega y Yarza, de que el pueblo había crecido en población pero no el número de clérigos, resaltando que el rector que atendía el culto divino en la iglesia de San Juan había huido con motivo de la peste, desamparando espiritualmente a los vecinos. Se trataba, en ambos casos, de presentar una situación catastrofica ante los jueces de la Chancillería con el fin de recuperar el patronato. Sin embargo Juan de Amézqueta interpretó inmediatamente la demanda del concejo: "...esto se (le)pedia...por le fatigar e hazer danno..." 80 .

La iniciativa, en consecuencia, no consistió solamente en presentar la correspondiente demanda ante el corregidor o la Chancillería. En ocasiones, co-

79 A. Duques del Infantado, Lazcano, Leg. 11, ${ }^{\circ} 11$ (1486).

${ }^{80}$ A. Real Chancillería de Valladolid, Pleitos Civiles, Quevedo, Fenecidos, C 793/2 (1509. 1510). Recoge una ejecutoria de 1490. 
mo ocurre en Zumárraga, Cegama, Hernani, Cestona o más tarde en Cizurquil o Berástegui, se percibe inmediatamente una evidente intencionalidad política, materializada en una estrategia perfectamente diseñada por los vecinos para desbancar al señor del disfrute de los derechos inherentes al patronato, o al menos limitarlo. Adoptan para ello todas aquellas medidas que podían socavar el reconocimiento de esos derechos en el entendimiento, según los vecinos de Hernani, de que los Alcega "...habian llebado las déçimas por el gran poder e mando que avia tenido en zquella tierra..." ${ }^{81}$. De la misma opinión eran los vecinos de Cestona que habían decidido desafiar el "ladrido del gran can" y arrostrar las represalias de su Preboste que, por otra parte, no dudaba acerca de Ia conspiración que los vecinos habían urdido contra él para desbancarle del ejercicio de los derechos de patronazgo: “...los parroquianos de la iglesia de San Miguell fesieron su ayuntamiento de privar al dicho Juan Beltran de su patronazgo e obligándose de tener a una segund se obligaron de faser unos por otros e asy fecha ha dicha obligaçion e pato iliçito presentaron al dicho don Juan de Insabsti como rector de la dicha iglesia e despues aca le ayudan con personas e dineros...acudiendole con gran parte de las desimas..." ${ }^{82}$. Por último, Juan López de Amézqueta tuvo que querellarse en 1490 contra los vecinos de Hernani porque, aunque habían llegado a un acuerdo en 1468 sobre los derechos de patronato de la iglesia de San Juan, "...avian tentado e que de fecho forçosa e violentamente contra el dicho contrato e contra el dicho su parte avian elegido e elegian a los clerigos..." $"$.

También el rector y los clérigos de algunas iglesias toman la iniciativa de enfrentarse al patrón. Este es el caso, durante los primeros años del siglo XV, del clérigo de Santa María de Astigarraga, Nicolás de Zomoza, “...presbitter dicte diocesis, sibi fecit de dicta ecllesia de Murguia tanquam de vaccante autoritate ecllesiastica provideri...". El enfrentamiento con Juan de Salcedo, a la sazón señor de la casa de Murguía y de Astigarraga, llevó a este a ocupar por la fuerza la iglesia y expulsar al cura al tiempo que reclamaba los diezmos. El presbítero excomulgó al señor y los parroquianos ${ }^{84}$. Finalmente, como se ha

81 A.M. de Hernani, E-4-II-1-1 (1490).

82 A. Real Chancillería de Valladolid, Pleitos Civiles, Zarandona y Walls, Olvidados, C 88/6 (1486)

${ }^{83}$ A. Real Chancillería de Valladolid, Reales Ejecutorias, C $29 / 21$ (1490).También en A. M. de Hernani, E-4-II-1-1.

${ }^{84}$ A. Diocesano de Pamplona, Caja 2422, $\mathrm{n}^{\circ} 1,(1422)$ : “...dominus Nicolaus de Çornoça, presbitter dicte diocesis, sibi fecit de dicta ecllesia de Murguia tanquan de vaccante autoritate ecllesiastica provideri, dictus vero dominus Joanis vigore dicti previllegii dictun dominum Nicholaun de dicta ecllesia expullit ypsumque ea spoliavit, et orte igitur lite sive controversia inter prefatos dominos Joannen et Nicholaun, gravis fuit inter eos discordia subcitata, dito domino Joanne cun potençia dictan ecllesiam ocupantem et ad sibi persolvendun dectimas parrochianos ipsius ecllesiae et incolas villae de Astigarraga compelente et compeli faciente, dicto vero Nicholao ypsun dominum Joannen ac

La época de Felipe II y los Austrias

Hispania Sacra 50 (1998) 
señalado, el señor legitimó sus derechos sobre Santa María en cuanto a la percepción de las décimas y la presentación de los clérigos ${ }^{85}$. Con todo, la reclamación de los clérigos gira usualmente en tomo al aumento de la congrua que perciben procedente de las rentas de la iglesia. Además, sus demandas son asumidas de uno u otro modo posteriormente por los parroquianos y el concejo de modo que el enfrentamiento acaba oponiendo al conjunto de la comunidad con el patrón. El caso de San Martín de Cegama ejemplifica esta situación: en 1442, el bachiller Ramiro Martínez de Ocáriz, clérigo beneficiado de San

prefactos parrochianos et incolas per censuram ecllesiasticam prosequente in tantum quod obtinuit iden Nicholaus dictun dominum Joannen ac ipsos parrochianos et incolas auctoritate ordinaria excomunicari et excomunicatos publice denunctiari ac ectian gravare et reagravare, ex qua quidem discordia nisi de çelere remedio exirisset provissum, multa grandiaque pericula et scandala provenissent et ad sedendum autem habeant discordiam sic gravem ac scandallosam, predicte partes cun aliquali spe concordiae inter eos perpefrato ad nos habuerunt recursum suplicantes...".

85 Ibidem, "...et ceterun cum ad nostrun officiun spectet de regimine ecllesiarum nostre diocesis ad exalfactionem divini cultus disponere volentes de espreso consensu predicti domini Joannis de Salcedo statuimus, disponuimus et mandamus quod de cetero per vicarium perpetuum predictum dominum Joannen tempore suo et eius subcessores dominos palatii nobis vel subcesoribus nostris presentandos per nos vel ipsos instituendi predicte ecllesiae serviatur ac regimen et curam ipsius tan in çelebractione officis divinis quam ecclesiariasticits sacramentis ministrandis et alits ad curam et regimem ipsius ecleesiae pertinentibus in eaden ecleesia regatur et exerçeatur et quod dictus vicarius habeat pro substentactione victe sue omnes oblactiones dicte ecllesiae in quibuscumque rebus consisfant et quod ultra hoc dictus dominus Joanis de Salcedo et eius subcessores heredes dictis palatii teneantur dare et conferre eiden vicario perpetuo perpetuis temporibus por suo slario quolibet anno quindectin floreneos de Aragonia solvendos videlicet sepcten floreneos cun dimidio pro festo Nativistatis Domini et reliquis seten cun dimidio pro festo Sancte Michaelis de mense setembris et omnes vero dectimas dicte ecllesiae in quibuscunque rebus decimalibus insurgant prefattis dominis Joanis de Salcedo eiusque subcessores et heredes domini de Murguia pro et nomine dicti palatii habeat et precipiat habentque ef precipiant perpetuis temporibus et de ipsis disponant por suo libito voluntatis ita tamen quod onera videlicet catredaticun et sinodaticun ac visitactionem et omnia allia hordinaria vel exhordinaria incunbenctibus ipsi parrochiali ecllesiae ac iure vel de consuetudine comodolibet et ex quacunque causa predictun dominum Joannem et eitus subcessores dominos dicti palatii perpetuo....et si forte dictus viccarius male se regerit et vita sua inoneste convictus fuerit, coram nobis vel subcessoribus nostris quod possit et debeat privari a dicta viccaria vel comoveri et allius idoneus predictun dominun Joannem vel eius subscesores heredes dicti palatii presentandus per nos vel subcesores nostros institui et nihilominus volumus ef ordinamus quod premictie dicte ecllesiae predictum viccarium diftum Joannen de Salcedo vel eius subcessores heredes dicti palatii perpectue regantur et distribuantur et de administractione per eos fienda teneantur reddere compotum sive ractionem quolibet anno preditto domino Joanne et eius subcessoribus heredibus dicti palactii vel deputando et deputandis per eos. Et si posquam per cuncta viccaria vaccaverit predictus dominus Joanis de Salçedo vel eius subcessores domini de Murguia infra tempus iuris personan idonean in viccarium perpetum nobis vel subcessoribus nostris presentare negligerint, quod nos ef subcessores nostri posint ponere vicariam, libere conferre et quoniam predictus dominus Nicholaus de Cornoca gessit pro rectore dicte ecleesiae, volumus et de consensu predicti domini Joannis ordinamus et mandamus quatenus iden dominus Nicholaus pro ut presentetur viccarium perpettum dicte ecleesiae per dictun dominum Joannen et per nos instituatur et dictam viccariam habeat iden dominus Nicholaus toto tempore vite sue...".

La época de Felipe II y los Austrias Hispania Sacra 50 (1998) 
Martín y Juan Ortiz de Cegama, patrón de la iglesia, se sometieron a un arbitraje para superar las diferencias que les venían enfrentando en torno al reparto de los diezmos y pie de altar. La sentencia de los jueces reconoció los derechos de patronazgo del Pariente Mayor, y se los negó al bachiller ${ }^{86}$, pero ordenó el reparto de los diezmos entre este último y el patrón para que se atendiera dignamente el culto divino ${ }^{87}$. Cuarenta y siete años más tarde, después incluso que los señores de Cegama, en 1455, lograran de Calixto III una bula reconociendo sus derechos sobre el patronato de San Martín ${ }^{88}$, el concejo de Cegama iniciaba un pleito reclamando los derechos de patronato sobre San Martín que finalmente consiguió en parte ${ }^{89}$. La Chancillería les amparó en la "...posesión de dicho patronazgo e derecho de presentar clerigo para rector e cura en la dicha iglesia..." pero, al tiempo, impidió que el concejo "...inquietase al dicho Martín Ladrón de Cegama en el llevar e resçibir e recaudar la dicha mitad de las dichas deçimas e oblaçiones de la dicha yglesia..."

${ }^{86}$ A. Histórico Provincial de Zaragoza, Hjjar, Sala I, Leg. 241/2, $\mathrm{n}^{\circ}$ 4.(1442): "...fallamos que el dicho monasterio de San Martin de Cegama es situado et fundado en heredad propia del dicho Iohan Urtis et sus antecesores et parientes e vesinos de la dicha vesindat et en siguiente que las heredades desmeras al dicho monesterio que son en la dicha vesindat son situadas en terminos de los dichos Iohan Urtis et sus parientes en tal manera que segund tenor del dicho privillejo et enformaçion los anteçesores del dicho Iohan Urtis et de los vesinos e moradores de Çegama llevaron et pudieron llevar el dicho monesterio et diesmos et derechos del con el dicho titulo del dicho privillejo dando capellan o vicario que sirviese la dicha yglesia de los divinos oficios et diese et administrase los sacramentos a los desmeros e parrochianos del dicho monesterio et que en siguiente fallamos que los dichos vesinos de Cegama anteçesores de los que agora son ovieron dado et traspasado al dicho Iohan Urtis e sus anteçesores todo su derecho que en el dicho monesterio avian por si e por sus herederos para siempre jamas e fallamos que el dicho lohan Urtis...e despues del sus herederos deven aver et mandamos que ayan el dicho monesterio con todos los diesmos et rentas e derechos del asi en pan en grano como en mançana, fruta, ganado, aves dinero,gera et pan cosido et todas las heredades et rentas que el dicho monesterio ha e le pertenescen...".

${ }^{87}$ Ibidem,"...Et por que el dicho Iohan Urtis deve e es.tenido de dar servido continuo que en la dicha iglesia sirva los divinos oficios et administre los sacramentos et aun segund la poblaçion $e$ vesinos que en la dicha vesindad ay en la dicha iglesia deve aver un vicario et servidor perpetuo et ydoneo et porque el dicho bachiller es pariente del dicho lohan Urtis et natural en la dicha vesindat mandamos al dicho lohan Urtis que aya, presente et tome por vicario del dicho monesterio al dicho Remiro Martines e...para en enmienda del dicho serviçio et ayuda de su mantenimiento del dicho bachiller et del capellan...que el dicho lohan Urtis de al dicho bachiller de oy para en toda su vida toda la meytad de todos los diesmos...".

${ }^{88}$ A. Historico Provincial de Zaragoza, Hijar, Sala I, Leg. 241/2, $n^{\circ} 5$. Se incluye en un documento de 1464.

89 Ibidem. Se paoyaron para ello en un incidente durante el cual Martín Ladrón de Cegama"...les avia fecho muchos abtos de perturbación feriendo e acuchillando los clérigos e que aun se fallaria que avia muerto a un don Juan de Yramarren en la dicha Yglesia la vispera dela Pascoa..." ",

${ }^{0}$ Ibidem. La sentencia puede encontrarse también en A. Real Chancillería de Valladolid, Reales Ejecutorias, C 51/35 (1489-1493)

La época de Felipe If y los Ausirias

Hispania Sacra 50 (1998) 
El enfrentamiento entre el rector y los clérigos con el patrón en torno al reparto de los diezmos dio lugar, en más de una ocasión, a una distribución de las casas dezmeras del pueblo que tributarán a uno y otro en el futuro ${ }^{91}$. También al encastillamiento de los clérigos en defensa de sus beneficios, como ocurre en la iglesia de Santa María de Zumárraga ${ }^{92}$. En estos casos las luchas entre ambos pueden ocultar también otros conflictos como el que habitualmente suelen mantener el rector o vicario de la iglesia con el resto de los curas en torno al reparto interno de las rentas que les asigna el patrón de modo que este último, incluso deseando incrementar el número de curas, se encuentra con la oposición de los clérigos que no quieren repartir el porcentaje de las rentas asignado a su mantenimiento ${ }^{93}$.

Los conflictos entre patronos y parroquianos/vecinos se resolvieron mediante las correspondientes sentencias de los jueces de la Audiencia de Valladolid o del Obispo de Pamplona, pero también mediante acuerdos y arbitrajes entre las partes. Unos y otros diseñaron, grosso modo, no solo el mapa de los patronatos laicos guipuzcoanos durante los siglos siguientes, sino también las constantes que determinaron en el futuro su administración ${ }^{94}$. En realidad, como ocurre respecto a otras fuentes de renta de los Parientes Mayores guipuzcoanos, la nueva ordenación resultante de las sentencias, acuerdos y arbitrajes entre las partes modificó, aunque fuera levemente en ocasiones, el anterior estado de cosas pero, en esencia, todo continuó igual al mantenerse prácticamente intactos los derechos de patronazgo de los Parientes Mayores sobre las iglesias. Ante la tensión generada con motivo de los enfrentamientos, la nueva ordenación fue el resultado de la cesión de los patronos que no dudaron en condescender ante algunas demandas de los parroquianos relacionadas con un servicio digno de los oficios divinos e incluso transigir con otras reclamaciones de los clérigos respecto al reparto de las rentas. Y todo ello con un solo

9I A. Rcal Chancillería de Valladolid, Pleitos Civiles, Moreno, Fenecidos, 1432/2 (1494)-1497). También en Zarandona y Walls, Olvidados, C 88/6, (1486).

92 Ibidem, Zarandona y Walls, Olvidados, C 1320/1,(1487). Estaban en Ia Iglesia "...los sobredichos clérigos cada uno de ellos con lanças e broqueles e espadas e ballestas desiendo e amenasando...que antes avian de morir que dexar de desir la misa al dicho don Juan...". El encastillamiento de los clérigos se produce con motivo del nombramiento de nuevos clérigos para la Iglesia de Santa María por el arcipreste de Pamplona. Fue necesaria la intervención del alcalde de la Hermandad.

${ }_{93}$ A. Real Chancillería de Valladolid, Reales Ejecutorias, C 99/5 (1496). En 1496, María de Yarza, patrona de la iglesia Santa Maria de Beasain, expuso ante los jueces de la Audiencia que en el citado lugar "...ay grand neşesidad de otro clerigo demas de lo que agora ay por la grandeza del pueblo e que es obligado a lo proveer e pagar don Iohan Barrena, clerygo de la dicha yglesia, el qual diz que son obligados la dicha donna Maria e su fijo..."Ibidem, Pleitos Civiles, Moreno, Fenecidos, $1432 / 2(1494-1497)$.

94 Véase Cuadro n ${ }^{\circ}$ 1: Iglesias de patronato laico en Guipúzcoa. Acuerdos y sentencias sobre su gestión derivados de los conflictos entre los patronos y parroquianos (1466/1521). 
objetivo: mantener el principal de los ingresos procedentes de las iglesias y su preeminencia social en la parroquia de su comunidad.

Las circunstancias que concurrieron en cada caso, incluida la coyuntural debilidad o fortaleza del Pariente Mayor, determinaron una solución más o menos favorable a los intereses de los parroquianos o del señor. Por ejemplo, en el caso del monasterio de Santa María de Balda, la muerte en el destierro de su patrón y el interés que sobre sus derechos se desató entre otros personajes, clérigos o laicos, con influencia en otras esferas de poder ajenas al linaje de Balda, provocó un sin número de incidentes, algunos de ellos ya señalados, en cuya corrección fue necesario contar con la representación política de los parroquianos, el concejo de Azcoitia, y con las más altas instancias del poder político y eclesiástico: el Rey de Castilla y el Papa. Todo ello con el exclusivo fin de conservar los derechos de patronazgo en el seno del linaje de Balda y obtener el necesario reconocimiento de las instancias de poder que podían hacerlo. El coste para el patrón fue, pese a todo, muy reducido: conservó el grueso de la renta y el reconocimiento de sus derechos a cambio de nombrar con acuerdo del concejo a los clérigos y que aumentara ligeramente el número de éstos. El ejercicio posterior de los derechos demostro, pese a las interferencias del concejo, el éxito de la operación que diseñó el de Licona para recuperar el patronazgo sobre el viejo monasterio de Santa María ${ }^{95}$.

Otros significados hidalgos guipuzcoanos también se vieron obligados a ceder para poder continuar manteniendo sus derechos. Los Alcega de Hernani, por ejemplo, entregaron al concejo, en 1468, algunos de sus privilegios sobre el viejo monasterio de San Juan, convertido ahora en iglesia parroquial. Lo hicieron no solo respecto al número de clérigos que debían servir los oficios sino también respecto a su futuro nombramiento, compartido desde entonces con el concejo ${ }^{96}$. También Lope de Arriarán, patrón de la iglesia de San Andrés, acordó en 1471 con los clérigos de la universidad de Ormáiztegui “...un contrato de composiçion e iguala e conveniençia...", mediante el cual el señor de Arriarán se comprometió desde entonces a presentar nuevos curas pero, simplemente, jcomo un parroquiano más! ${ }^{97}$. En el caso de los Oñaz y Loyola,

95 Sobre esta cuestión esta publicada prácticamente toda la documentación en la colección Fuentes documentales medievales del País Vasco, por $\mathbf{M}^{\mathrm{a}} \mathrm{R}$. AYERBE, Documentación Medieval del Archivo Municipal de Azkoitia (m.s. XIII-1500), San Sebastián, 1993, documentos 36, 37, 48, 49, 51, 57 y 77.

96 A. Real Chancillería de Valladolid, Pleitos civiles, Quevedo, Olvidados, C 793/2, (15091510): "...que daba e donaba al dicho monasterio para agora e para siempre jamas todas las dichas ofrendas que en el dicho monesterio e sus vaselicas que son o fueren en la dicha parrochia fueren ofresçidas asy barones o mugeres grandes o pequennos parrochianos como todo el pie de altar mayor $e$ de qualesquier otros allares que ayan o fueren en la dicha yglesya...".

97 A. Diocesano de Pamplona, Procesos, C 2756, $\pi^{\circ} 5$ (1512).

La época de Felipe II y los Austrias

Hispania Sacra 50 (1998) 
el patrón, como ha demostrado José Antonio Marín, consciente quizá de su difícil posición frente al concejo, con el acuerdo de los clérigos, repartió con el rector y los siete beneficiados de San Sebastián los diezmos y el pie de altar que recibía como patrón ${ }^{98}$. Se trataba de garantizar por escrito a los sacerdotes el futuro de sus respectivas congruas, del mismo modo que algunos pleitos entre señores y concejos tienen como consecuencia un reparto preciso de las rentas. En Beasain, los Yarza y los clérigos de Santa María pelean por las casas que deben pagar los diezmos a cada uno de ellos, pero el problema de fondo es el reconocimiento entre ambas partes del $50 \%$ de las rentas ${ }^{99}$. Idéntico reparto de las rentas que el establecido entre los Parientes Mayores de Olaso y el concejo de Eibar en el caso de la iglesia de San Andrés ${ }^{100}$.

En alguna ocasión, sin embargo, la cesión va más allá, hasta el punto de reconocer los derechos de patronato al concejo de turno. He tratado anteriormente el ejemplo de Martín Ladrón de Cegama. En este caso el señor mantuvo el 50\% de las rentas sobre San Martín pero perdió en la Chancillería el derecho de presentación de los clérigos. No ocurrió lo mismo en el del preboste de Cestona, Juan Beltrán de Iraeta que, en 1483, con motivo del enfrentamiento que mantenía con el concejo llegó a reconocer públicamente que no estaba “...enteramente informado de la verdad nin del derecho del patronazgo de vos el dicho concejo e parroquianos a patronos susodichos como agora estoy $e$ soy ynformado e pues ansy he seydo ynformado e se por entero que la dicha presentaçion e patronazgo hera e es e pertenesçe e compete totalmente a vos el dicho conçejo veçinos e parroquianos e patronos..." $\mathrm{y}$, en consecuencia, siendo "...sabidor e çierto e çertificado que a mi e a mi honrra e provecho de la dicha mi casa e solar de Yraeta cumple e conviene averme bien e pasar con vos los susodichos parrochianos e patronos en amistad e amorio e concordia e syn debates...la qual honrra yo non podria aver nin sostener aviendo question con vos los dichos conçejo e veçinos ...", reconoció al concejo los derechos de patronato que disputaban: "...otorgo e conosco queel derecho de la presentaçion del dicho rector e rectoria de la dicha yglesia de Santa Maria de Ayçarna e la presentaçion del vicario e vicaria de la dicha yglesia de Santa Cruz de Çestona e todo otro total e entero derecho del dicho patronazgo preeminençias e previlegios $e$ universal derecho corresponde a vos el dicho

98 J.A. Makín “Semejante Pariente Mayor"..., o.c., pp. 322 y ss.

99 A. Real Chancillería de Valladolid, Reales Ejecutorias, C 99/5, (1496). Dos años antes el "...rector perpetuo de la iglesia de Santa Maria de Beasain dis que los sennores cuya es la casa e solar de Yarça dis que a cabsa de ser los tiempos pasados rotos e de poca justiçia como fueron dis que por fuerça e contra su voluntad le han llevado e llevan la mitad de sus diezmos que a la dicha yglesia se diesman e que le pertenesçen a el como rector..." (A.G.S./R.G.S., X-1494-fol.492).

100 A. Real Chancillería de Valladolid, Pleitos Civiles, A. Rodriguez, Fenecidos, C 1625/1, (1506). 
conçejo e veçinos e parrochianos e patronos susodichos..." ${ }^{101}$. Este testimonio, presentado como prueba por los vecinos, solo puede entenderse en el marco de la extrema debilidad del patrón frente a los parroquianos. Dos años más tarde, con motivo de la renovación del patronato sobre las iglesias y el prebostazgo sobre la villa, el sucesor del "gran can", olvidó sus promesas y reconocimiento y continuó nombrando a los clérigos y recaudando las rentas.

Frente a este conjunto de cesiones, más o menos explícitas, destaca en sentido contrario el comportamiento de los grandes linajes de la tierra guipuzcoana: Guevara y Lazcano. En el caso de los Guevara y sus derechos sobre San Miguel de Oñate, el primer conflicto serio entre el patrón y el concejo y los clérigos no tuvo lugar hasta 1540 , cuando a juicio de $\mathrm{M}^{\mathrm{a}}$ Rosa Ayerbe, se puso en tela de juicio el señorío jurisdiccional y se solicita la vuelta al realengo. El problema terminó dos años más tarde con un acuerdo entre las partes ${ }^{102}$. En cuanto a Santa Marina de Oxirondo los enfrentamientos entre el patrón y los clérigos y particulares que intentaban apropiarse de sus rentas se remontan a 1452 dictándose dos Capitulados en 1467 y 1495 para el buen gobiemo del monasterio. El de Guevara continuó en todo caso percibiendo sus rentas hasta 1508 , fecha en que hubo de cederlas en pago de la dote de la boda de su hermana con Lope García de Salazar ${ }^{103}$.

Por su parte, los de Lazcano, inmersos en la gestión de las tierras alavesas que querían escapar de su señorío, tuvieron que utilizar todos los recursos a su alcance para superar dos sentencias condenatorias ganadas por los parroquianos de Santa María de Zumárraga que les discutían el derecho de patronato en la Chancillería de Valladolid. Junto a los argumentos utilizados en las sucesivas apelaciones seguramente también utilizaron su influencia en la Corte explotando el asesinato en Contrasta, apenas unos años antes, de Juan de Lazcano, Pariente Mayor del linaje. Todo ello permitió finalmente a los Lazcano, pese al incremento del número de clérigos y el antecedente que supuso para el concejo, mantener dos tercios de las rentas ${ }^{104}$. Apenas un año más tarde los responsables de la gestión del patrimonio de los Lazcano diseñaron, sin duda con el fin de mantener intacto el núcleo de sus ingresos procedentes de sus iglesias propias, una política de acuerdos con los curas, parroquianos y vecinos de Idiazábal ${ }^{105}$, Olabarría ${ }^{106}$, Mutiloa ${ }^{107}$ o Ataun ${ }^{108}$ que se extendió hasta 1521.

\footnotetext{
101 lbidem, Pleitos Civiles, Masas, Fenecidos, C 3554/2, (1528-1533).

102 Historia del Condado..., o.c, pp., 524-528.

103 Jbidem, pp. 553-564.

104 A. R. Chancillería de Valladilid, Pleitos Civiles, Zarndona y Walls, Olvidados, C $1320 / 1$ (1487). También en A. Duques del lnfantado, Lazcano, Leg 11 n 11 .La sentencia es de 1489.

${ }^{105}$ A. Diocesano de Pamplona, C $715, n^{\circ} 2$ y C $189 n^{\circ} 4$.También en A. Duques del Infantado, Lazcano, Leg $9 \mathrm{n}^{\circ} 1$.

${ }^{106}$ A. Duques del Infantado, Lazcano, $\operatorname{Lcg} 8 \mathrm{n}^{\circ} 2\left({ }_{(} 1492 ?\right)$. 
Adviértase que se trata en todos los casos de iglesias rurales a las que se aplica el mismo modelo. En primer lugar, se cede habitualmente a la solicitud de los parroquianos para aumentar el número de clérigos pero conservando el derecho de presentación de los mismos, cumpliendo las condiciones establecidas con el concejo, es decir, que los clérigos sean “...naturales, $e$ originarios $e$ bautizados e continuos habitantes en la dicha colacion..."; en segundo lugar, se asigna a los clérigos y al culto, $1 / 4$ de las décimas y el pie de altar que en cada caso corresponda mientras el patrón se reserva los $3 / 4$ restantes. Todo parece indicar que se trata de garantizar por escrito, ante la presión del entomo y de los propios partoquianos, las condiciones por las que se regirá la institución en el futuro, asegurando tanto la congrua de los clérigos como las rentas del señor. En todo caso el modelo se perpetuará prácticamente sin modificaciones durante los siglos siguientes.

Con todo, las sentencias dictadas por la Chancillería de Valldolid o los acuerdos entre las partes, no resolvieron las tensiones entre patronos y parroquianos. En realidad este fue un conflicto latente que se manifestó de un modo intermitente cuando se acentuaban las arbitrariedades de los señores, con motivo de la merced de los derechos a un nuevo patrón: en el momento de una minoría de edad del patrono o cuando señor y concejo estaban enfrentados por otras causas. En Hernani, en Cestona o en Azpeitia los enfrentamientos rebrotaron continuamente al compás de las nuevas circunstancias políticas y sociales que marcaban con su impronta una relación conflictiva entre quienes defendían sus viejos derechos y los que querían arrumbarlos. Las razones del enfrentamiento continuaban siendo las mismas pero, una vez definida la participación en la renta de las iglesias, fueron los privilegios que representaban la preeminencia social dentro de ellas y encarnaban el reconocimiento de los derechos de patronato, los que multiplicaron los enfrentamientos.

Como si se tratara de una obligada traslación de los conflictos en el exterior de la iglesia al interior de sus muros, al compás de las nuevas circunstancias políticas y sociales, la ubicación de los fieles en el interior de la iglesia tanto durante la vida, en los actos religiosos, como después de muertos, en sus tumbas, se convierte en un asunto central para la comunidad. El enfrentamiento se produce ante todo entre el patrón y los partoquianos de la iglesia de turno ${ }^{109}$. Pero también entre los viejos y los nuevos patronos, entre aquellos que habían

\footnotetext{
107 A. Duques del Infantado, Lazcano, Leg $10 n^{\circ} 1(1510)$.

108 A. Duques del Infantado, Lazcano, Leg $14 n^{\circ} 1(1521)$

${ }^{109}$ Sobre esta cuestión fue necesario que se pronunciasen los monarcas en 1494, ordenando que "...ningunos nin algunos vecinos de la dicha provinçia non tengan nin defiendan sus lugares conocidos en las dichas iglesias e monasterios nin algunos dellos reservando su derecho a los patrones de las dichas iglesias e monasterios si alguno tienen...".
} 
disfrutado hasta entonces de los derechos de patronato y quienes los reciben nuevamente o aquellos otros cuyo ascenso social, gracias fundamentalmente al desempeño de oficios en la Corte, necesita la confirmación de su superioridad en la nueva sociedad guipuzcoana que va conformándose al final de la Edad Media. Para conseguirlo nada mejor que una merced real cediéndole el patronato sobre una o varias iglesias hasta entonces en manos de un viejo Pariente Mayor y su consiguiente ubicación en el lugar más preeminente de cada una de ellas cada vez que asiste a los oficios religiosos. Así ocurrió en 1497 con la merced de los Reyes Fernando e Isabel a su Repostero de Cámara, Pedro de Idiáquez ${ }^{10}$.

Pero quizá el mejor ejemplo, aquel a través del cual se aprecia una deliberada búsqueda de manifestar y representar ante el resto de la comunidad el grado de supremacía alcanzado, es el que nos proporciona Juan López de Lazárraga, contador y testamentario de Isabel la Católica. Oñate no era el mejor lugar para demostrar su condición. El Conde de Oñate difícilmente podía aceptar una exteriorización cómo la que pretendía el de Lazárraga: levantar su sepultura en la capilla de la Piedad del Monasterio de San Miguel, cuyo patronazgo ostentaba el de Guevara. Ofreció al conde más de 2.000 ducados, pero obtuvo una respuesta negativa. Tampoco era posible en Oñate una merced real sobre los derechos de patronato del Guevara. Asunción Arrázola ya señaló que el Contador, ante la negativa, respondió con "la institución y dotación del convento de la Santísima Trinidad de Bidaurreta", para mayor gloria y honor de su linaje y para levantar en el su sepultura. Allí descansó su cuerpo como había dispuesto: "... a la parte del evangelio y el cuerpo de mi muger a la parte de la epistola..." y junto a ellos, con la sencillez que había determinado, los escudos de ambos $" 1$. Los más significados miembros de la nueva élite social guipuzcoana soñaron enterrarse de ese modo, pero solo el Contador lo logró. Del mismo modo que obtuvo una cédula real que impedía al Conde de Oñate, señor del valle, aposentarse en su casa. Solo la reina y sus hijos podían hacerlo ${ }^{112}$.

110 A. Real Chancillería de Valladolid, Reales Ejecutorias, C 178/8 (1503): “...acatando los muchos e buenos serviçios que nos avedes fecho e façedes de cada dia e en alguna enmienda e remuneraçion dellos tenemos por bien $e$ es nuestra merçed $e$ voluntad que agora e de aqui adelante para en toda vuestra vida tengades e gozedes los diezmos e ofrendas e pie de altar de las parrochias e monasterios de Sant Millan de Ciçurquil e Santa Maria de Aduna que son en la tierra provinçia de guipuzcoa en lugar e por vacaçion de Martin Ruyz de Sant Millan patron que fue de los dichos monasterios por quanto el es fallesçido e pasado desta presente vida...". En 1531, Carlos V donará a Alonso de Idiáquez los patronatos que hasta entonces disfrutaba el preboste de Cestona. A.H.P. de Zaragoza, Hijar, Leg. $6 \mathrm{n}^{\circ} 2$.

$11{ }^{\prime}$ El Renacimiento en Guipúzcoa, Tomo 1, Arquitectura, San Sebastián, 1967, pp. 54-55.

112 A. Duque de Sotomayor, Lazárraga, Leg.1, $\mathrm{n}^{\circ} 30$ (1508). “...que vuestras casas donde vos teneis vuestra morada en la villa de Oñate e las casas...de Bidaurreta ...sean para siempre jamas libres $e$ exentas de huespedes $e$ que los conces e condesas e sennores que son o fueren de la dicha vi-

La época de Felipe II y los Austrias

Hispania Sacra 50 (1998) 
Mientras quienes accedían por primera vez a los derechos de patronato sobre las viejas o las nuevas iglesias hacían suyos los comportamientos de los Parientes Mayores en el pasado, los concejos que ostentaban el patronato de las parroquias de las villas actuaban del mismo modo. En esos concejos, quienes se habían enriquecido con el comercio o los oficios públicos quisieron también dejar constancia de su superioridad frente al resto de la comunidad construyendo capillas en el interior de la iglesia. En algún caso, además, como ocurrí en Zumaya, dos significados miembros de la nueva élite social guipuzcoana, el bachiller Sasiola, y Juan Pérez de Elorriaga, no sólo construyeron sendas capillas sino que además pretendían colocar sus bancos en las gradas de las mismas, marcando de ese modo su preeminencia social frente al resto de los vecinos y, por último, impedir que los bancos de estos se situaron frente a ambas capillas. La sentencia no sólo fue favorable al concejo, que pleiteó con ellos, autorizando que se colocasen bancos delante de las dichas capillas, sino que expresó de un modo contundente las prebendas asociadas al patronato en el interior de la iglesia. En primer lugar correspondía un sitio preeminente a quienes ostentaban o habían ostentado colectivamente los derechos de patronazgo: "...e mandaron que en sennal que el verdadero patronazgo residia e reside en el cuerpo del dicho concejo que, en la cabecera de los dichos dos bancos, se ponga e asienten para secula seculorum los alcaldes que en la villa fueren $e$ subçedieren, el mas antiguo a la parte de la capilla que fizo el dicho bachiller $e$ el otro en la otra parte...". En segundo lugar debía situarse el resto de los vecinos: "...e mandaron que todos los bancos fuesen comunes e que en ellos se sentasen quien quier que en ellos quisiese asentar e ninguno fuese osado de apropiar asyento para sy et mandaron que quedasen en libertad al dicho conceçejo de quitar los dichos bancos cada vez que quisyesen e como les fuese mejor visto e mudarlos e pasarlos e fazer a su voluntad..." 113 .

Pero, como he anunciado, la ubicación de los individuos una vez que han abandonado el mundo de los vivos es también un asunto de principal importancia para la comunidad. El patrón y algunos miembros de la élite local que se habían enriquecido gracias al comercio o a los oficios aseguraron para el futuro su superioridad colocando sus tumbas y las de sus familias en los lugares

Ila...non puedan ser aposentadas en las dichas vuestras casas...salvo si acaesçiere que yo o qualquier de mis fijos...".

113 A.Municipal de Zumaya, Libro $17 \mathrm{n}^{\circ} 28$ (1510). Una vez dictada sentencia Juan Lopez de Sasiola "...se desistia e desistio del dicho pleito e renunçiaba e çedia e renunçio e çedio todo el dicho derecho contrael dicho concejo si alguno tenia...". Adviertase, sin embargo, que semejantes sentencias, pese a su aparente contundencia, no resolvieron para siempre el problema. Los herederos de estos Sasiola que habían adoptado también el nombre de Zumaya seguian pleiteanđo con el concejo en 1579 ante el Obispo de Pamplona intentando nuevamente hacer valer sus viejos derechos (A. Diocesano de Pamplona, C 67 n$^{\circ} 21(1579)$. 
preferentes: junto al altar mayor, en el lado del Evangelio o en las capillas que fueron abriéndose en los laterales de las iglesias. El resto de los vecinos en el suelo de cada una de ellas. La distribución en planta de las sepulturas debió reflejar en algún momento una paralela disposición de la preeminencia social que cada una de las familias ostentaba durante la vida de sus individuos ${ }^{14}$.

Finalmente, como en la cercana Vizcaya, un modo de terminar con el patronato de los Parientes en determinadas villas y lugares fue la aspiración de crear y construir nuevas iglesias. Los vecinos y parroquianos, en efecto, tomaron la iniciativa tratando de mejorar las condiciones de las viejas iglesias en tomo a las cuales se desarrollaba la vida espiritual de la comunidad al tiempo que trataban de sacudirse el patronazgo del Pariente Mayor de turno. En el caso guipuzcoano, sin embargo, en ninguno de los ejemplos conocidos, la construcción de una nueva iglesia nunca se tradujo en la revocación de la merced de patronato al beneficiario. La correspondiente licencia siempre contemplaba la salvaguarda de esos derechos como advertencia a los vecinos aunque, ciertamente, algunas condiciones cambiaron radicalmente para el patrón fruto de las nuevas circunstancias políticas y sociales. En todo caso la erección de una nueva iglesia constituyó siempre una fuente de conflictos entre patronos y parroquianos, especialmente graves y al parecer violentos cuando algunos feligreses se desgajaban de la iglesia en la que hasta entonces pagaban sus diezmos ${ }^{115}$.

La primera noticia que conozco del proyecto de una nueva iglesia se refiere a la parroquial de San Juan de Hernani, bajo patronazgo en 1483 de Juan L6pez de Amézqueta. Los vecinos habían realizado su propuesta aludiendo a la dificultad de cumplir adecuadamente con los oficios divinos ${ }^{116}$ y contaban para

114 Algunos estudios arquitectónicos realizados en iglesias, como ocurre en la de Nuestra Señora de la Asunción de Rentería, muestran la distribución en planta de las sepulturas E. VÁzQuEZ y K. Muro, Nuestra Señora de la Asunción de Renteria. Estudio Histórico-artístico, San Sebastián, 1993. Incorpora un plano de Rafael Nin̄o.

its Este parece ser el caso, durante los primeros años del siglo XVI, de los vecinos del barrio de Zumea y de la casería de Albachitibar que se consideraban parroquianos de la iglesia de San Martín de Andoain contra el criterio del sethor de San Millán que pretendía que diezmaran en la iglesia de San Millán de Cizurquil. Los vecinos "...con muchas armas e por fuerça dellas tomaron a Martin Ruyz de San Millan e a los que con el estaban los diesmos que le avian pagado los de la dicha juredicion de Cumea e asy le despojaron de la posesion en que estaba de cobrar e recabdar la mitad de las dichas degimas...que puede valer en cada anno veynie florines de oro de cunno de Aragon...". A. Real Chancillería de Valladolid, Reales Ejecutorias, C 224/40 (1508). Hay también abundante información sobre esta cuestión en Pleitos Civiles, Moreno, Fenecidos, C 745/2 (1503-1508).

116 A.G.S./ R.G.S., X-1483, fol. 291"...la iglesia de Sant Juan de tiempo ynmemorial a esta parte hera igleisa parrochial de la dicha villa, la qual por estar como esta fuera de los muros della e non aver otra yglesia en esta dicha villa, los oficios divinos non eran en ella administrados segund devian e los hombres viejos e impedidos de algunas enfermedades e otros ympedimentos que aquel ynvierno con las muchas niebes...que acaesçia non padian yr ni iban so peligro de sus personas a la dicha yglesia ...".

La época de Felipe Il y los Austrias Hispania Sacra 50 (1998) 
el traslado con la licencia del obispo de Pamplona y de los reyes Fernando e Isabel "...para que la dicha iglesia antigua de San Juan fuese mudada e trasladada dentro de la dicha villa...". Sin embargo, el de Amézqueta se quejó ante los monarcas de las consecuencias y perjuicios que pudiera tener para sus derechos sobre la iglesia, de modo que la autorización para trasladarla se hizo con la expresa condición de que "...si la dicha iglesia fasiades que la non fasieredes con intençion de perjudiar a nos en el derecho que en la dicha iglesia antigua tenemos nin a la persona que de nos della tiene merçed antes que vos..." 117 .

El ejemplo mejor documentado es, sin embargo, el de la iglesia de Santa María de Azcoitia. Los vecinos, al amparo de un hospital que "...se fizo en tiempo que la dicha villa estaba muy dapnada de pestilençia", crearon un centro de culto al que entregaban mandas y limosnas para su mantenimiento. Quizá fue un intento de instaurar el embrión de una parroquia paralela. En algún momento así parece percibirlo el de Balda ${ }^{118}$. Incluso el hospital de San Sebastián fue en aquellos años centro de reunión del concejo ${ }^{19}$. Por otra parte, en la vieja iglesia de Santa María de Balda se habían realizado algunas obras de ampliación y acondicionamiento en torno a $1497^{120}$, pero no fue hasta 1509 cuando la reina Juana ordenó la construcción de un nuevo edificio en las inmediaciones de la villa ${ }^{121}$. Las condiciones establecidas por la reina para la

\footnotetext{
117 Ibidem.

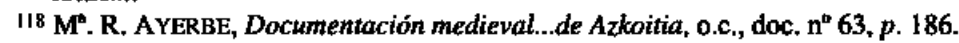

119 bidem, doc. $\mathrm{n}^{\mathrm{a}} 73$, p. 212.

$120 \mathrm{Jbidem}$, doc. $77, \mathrm{pp} .218$ y ss.

${ }^{321}$ A. M. Azkoitia, Leg. 6 n' 2, (1509): “...la yglesia parrochial de Santa María de la villa de Azcoytia...de mi patronazgo real, esta en una cuesta alta fuera y lexos de la dicha villa e que a esta causa muchos vesinos y enfermos dexan de yr a oyr misa y visperas y los otros officios divinos que en ella se dizen y celebran y que asy mismo los clerigos que los dizen o algunos dellos asi por la dicha distançia et despoblado como por sus edades y otros respectos non van a los tiempos que deven a dezir los dichos oficios nin administran los santos sacramentos con la brevedad que se piden y son necesarios y asy por serviçio de Dios nuestro Setior como por escusar los dichos inconvenientes y otros muchos y por el beneficio, descanso y ennoblecimiento de la dicha villa y aplicacion della he acordado que se traslade la dicha yglesia a unas huertas que ay junto a la dicha villa y el arrabal que diçen de Basterrica que han por linderos la dicha villa e arrabal y el rio de Legazpia y el campo Real que va para Vergara con tanto que en el dicho traslado me quede el mismo derecho de la provision del dicho patronadgo que agora tengo e me pertenesçe en la dicha yglesia...e vos mando e que por vertud de la carta de creencia. supliqueys de nuestra parte a su \$antidad le plega dar liçençia para que se pueda trastadar la dicha yglesia a las dichas huertas con el serviçio diezmos e premicias curadgos e benefiçios proventos y emolumentos y con el çiminterio e enterrorio, pila, capillas $e$ capellanias, campanas $e$ ornamentos $y$ otras cosas a la dicha yglesia y a la parroquia della anexas e pertenesçientes y porque la dicha yglesia tiene mucha piedra e madera labrada que ayudara mucho para el edificio del dicho traslado que ansy mismo le plega dar liçençia para que aquello se pueda derribar e llevar a la dicha yglesia nueva quedando tan solamente en la primera una hermita de la manera e condigion de las otras que ay en la dicha juredicion de la dicha villa con advocacion de Santa Marla el Antigua y que la misma advocacion de Nuestra Señora que fasta aqui tenga la dicha yglesia que asy se trasladare...".
} 
"traslaçion e mudaçion" de la iglesia chocaban con los intereses de Hernando de Balda, nieto de aquel Licona que había recuperado para el linaje los derechos de patronato sobre la iglesia. Tomando como excusa "la mucha contia de maravedis que diz que valian los edificios de la nueva iglesia" remitió, en ese momento crucial, una serie de peticiones a la reina. Era el último intento del patrón para conservar sus privilegios. El Consejo Real los definió concretando para el futuro el ejercicio de los derechos que correspondían al de Balda y a los parroquianos tanto en la vieja como en la nueva iglesia ${ }^{122}$. En esencia el de Balda logró no sólo mantener el título de patrón y los derechos asociados tradicionalmente al patronazgo: presentación de los clérigos, percepción de los diezmos y las preeminencias acostumbradas, sino también que la vieja iglesia continuara siendo una ermita donde pudieran seguir descansando sus antepasados. No pudo obtener, sin embargo, 'que las armas de su linaje, que estaban puestas en la capilla principal de la vieja iglesia, se trasladasen a la nueva. El Consejo consideró que al ser solamente patrón " por su vida" era el escudo de armas de la reina el que debía colocarse en lugar preferente en Santa María la Real.

El concejo de Azcoitia se consideró "agraviado" por las decisiones del Consejo Real. Sus demandas, sin embargo, no cuestionaban el núcleo principal de los derechos del patrón. Consideraba injurioso, por el contrario, un conjunto de ventajas relacionadas con la ubicación del patrón y los parroquianos durante los oficios divinos y con la disposición de los enterramientos de uno y otros en la nueva iglesia, construida en terrenos comprados por el concejo. En efecto, se había dispuesto que "...el dicho Hernando de Balda e los vicarios e manobreros entendiesen en sennalar las sepulturas e asientos de los ombres e mugeres non hasiendo memoria del dicho conçejo...". También, "...que el patron tenga una silla al lado del evangelio, arrimada a la pared, algo más alta que las otras...", un derecho que sus antecesores no habían disfrutado y que se había "...inventado de veynte annos a esta parte de le poner sobre las gradas çerca del sagrario, a la mano derecha del altar, $e$ que antes alli non avia asiento ninguno...salvo que los que non tenian asientos conosçidos se subian sobre las gradas...". Del mismo modo, en cuanto a la tumba del patrón, el concejo denunciaba que "... que quando se començo a poner hera pequenna, como una sepultura e agora la ponian muy grande e alta..." y que junto a ella el de Balda "...pretendía poner un escanno para su muger e su madre...muy grande...e a un lado haser otros asiento para sus mugeres (criadas)...". Era por tanto la representación diaria y para la etemidad, en el interior de la iglesia, de la supremacía del patrón y de su familia frente al resto de los habitantes de la villa, el motivo esencial de los enfrentamientos. Una superioridad que ya nada tenía que ver con las nuevas circunstancias económicas y sociales de la

122 A. M. Azkoitia, Leg. 9 n$^{\circ} 11$ (1514).

La epoca de Felipe II y los Austrias

Hispania Sacra 50 (1998) 
villa y de la Provincia. Más aún cuando "...la dicha villa es de mi corona real e el dicho conçejo avia comprado el suelo para haser la dicha yglesia..." ${ }^{123}$.

\section{A MODO DE CONCLUSIÓN.}

En las páginas anteriores he intentado explicar las características de los derechos de patronato que disfrutaban los Parientes Mayores sobre las iglesias guipuzcoanas. Confío que ahora pueda entenderse mejor, como pretendía adelantar el título del trabajo, que la titularidad de aquellos derechos no sólo constituyó una fuente de ingresos regular y segura para los cabezas de linaje de ese territorio, sino que también, su continuado ejercicio entre los siglos XIV y XVI, puso en sus manos un instrumento de control y dominación social y política sobre los parroquianos de las universidades y las villas de Guipúzcoa. Ingresos e instrumentos que colaboraron notablemente a construir, asentar y perpetuar el poder de los Parientes en los estrechos ámbitos territoriales de su influencia.

El lado material y el lado político-ideológico que implica el ejercicio de esos derechos son inseparables. Son dos caras de la misma moneda. A menudo la importancia cuantitativa de los ingresos derivados de esos derechos puede parecer lo más relevante. Pero, incluso cuando el porcentaje de los mismos superaba con creces el $50 \%$ de los ingresos anuales del linaje, resulta prudente resaltar paralelamente tanto la trascendencia del nombramiento de los clérigos como la permanente visualización de la preeminencia del patrón tanto durante su vida como después de su muerte frente al resto de la comunidad. Así se aprecia de modo concluyente cuando se inician las tensiones entre el patrón y los parroquianos en torno al disfrute de los derechos de patronazgo de las distintas iglesias guipuzcoanas. No sería posible explicar su importancia sin considerar al mismo nivel ambos aspectos.

Pedro López de Ayala, como portavoz de los intereses de los hidalgos y buen conocedor, como patrón que era, de las circunstancias que rodeaban a las iglesias de patronato laico al final del siglo XIV, relata en su Crónica los hechos que se sucedieron durante las Cortes de 1390 , y de modo especial la argumentación jurídica utilizada por los hidalgos para defender su posición frente a los prelados de Calahorra y Burgos, en la que asociaron la percepción

123 Ibidem. Finalmente el corregidor de Guipúzcoa determino cl tamaño que debía tener la sepultura del patrón "...dos codos e medio de ancho e de tres cuartas de vara medir de alto..." y que " ..,non se ponga escanno alguno cerca de la tumba para la muger del patron...". Tumba y asiento preferente que desaparecerian cuando terminara la concesión real. 
de los diezmos de sus iglesias con el "conoscimiento del señorio general"124. He ahí la cuestión central en la defensa y en el ejercicio de los derechos de patronato. Semejante relación entre patronato y señorío explica perfectamente el interés que despierta entre los cabezas de linaje guipuzcoanos la cesión real de la administración de esos derechos y el consiguiente reconocimiento de los mismos por la comunidad donde se asienta el solar del nuevo patrón. Del mismo modo ilumina y dimensiona los conflictos que se sucederán especialmente durante la segunda mitad del siglo XV en torno a esos derechos y que van más allá de la aparente prestación más o menos digna de los servicios relacionados con el culto divino y deben ser interpretados como una manifestación más de los movimientos antiseñoriales que protagonizan las gentes de las universidades y las villas guipuzcoanas frente a los Parientes Mayores.

En efecto, los Parientes defendieron sus derechos en el entendimiento de que estando en peligro el ejercicio de los derechos de patronato no sólo lo estaban sus rentas sino también la preeminencia social y política en el seno de su comunidad, la cual a su vez llevaba implícita una suerte de reconocimiento de señorío. Del mismo modo los parroquianos, es decir, los vecinos de las universidades y villas guipuzcoanas con iglesias de patronato laico, pleitearon con los señores sabiendo que lo que estaba en juego no era solamente el número de clérigos o como se repartirian los diezmos y las ofrendas en el futuro, sino que la vuelta al patronato real de la iglesia de turno implicaba también el final del reconocimiento de aquella fórmula de señorío al patrón que hasta entonces administraba los derechos reales. Así lo consideraban también aquellos nuevos elementos de la élite guipuzcoana que habían hecho fortuna especialmente desde el desempeño de oficios en la Corte - Lazárraga, Idiáquez-, que durante los años finales del siglo XV y la primera mitad del siglo XVI aspiraron y consiguieron la cesión temporal de la administración de algunos patronatos.

El resultado final, el modo en que se resolvieron las tensiones entre patronos y parroquianos mediante el establecimiento de una regulación sobre como debían administrarse en el futuro esos derechos, refleja los cambios que se derivan de las nuevas circunstancias políticas y sociales : los Parientes y también la nueva élite de la sociedad guipuzcoana que había accedido a los derechos de patronazgo, continuaron disfrutando de la supremacía sobre el resto de la comunidad. Todo continuó aparentemente igual, sin embargo, tanto el hecho

\footnotetext{
124 Pero López de Ayala. Crónicas, op. cit., p. 687." Señor, en lo que dizen que estos diezmos tales non caen en persona de lego dicennos los letrados que los diezmos son debidos a las iglesias por una de dos maneras: la una por reverencia e acatamiento del servicio divinal que en ellas se faze $e$ tal diezmo como este que es puro espiritual non le puede aver lego nin levar las tales rentas; la otra por razon del conoscimiento del señorio general, e en este caso puede levar el lego los frutos; e este es el caso por do nosotros levamos los tales diezmos"
} 
de que se fijara por escrito una determinada forma de ejercer los derechos y se eliminaran de ese modo las arbitrariedades de los patronos, como las nuevas circunstancias políticas, asociadas al desarrollo de las nuevas instituciones provinciales de las que quedaron desplazados los Parientes Mayores, dieron un nuevo sentido al disfrute de los derechos de patronato sobre las iglesias en el que ya no es posible reconocer atisbo alguno de aquel "conocimiento de señorío general" que reivindicaban los hidatgos en 1390. A principios det siglo XVI aquel señorio había cambiado de sentido y solo cabe interpretarlo como expresión de la mayor distinción, grandeza o nobleza de aquellos que disfrutaban de los derechos inherentes al patronato. En 1518, con motivo de una reunión mantenida con anterioridad por buena parte de los Parientes Mayores expresamente prohibida por las Ordenanzas de la Hermandad, su procurador adujo como justificación que "...los dichos Parientes Mayores, como son anteriores y mejores y fundadores de esta Provinçia, siempre han usado e usan e usaran de syrvyr a sus altezas con sus armas y caballos y escuderos y parientes, en espeçial contra los enemigos de la santa fee catholica asi como contra moros e turcos e otros infieles, por lo qual tienen sus patronazgos y deçimas asy por mano de sus Altezas como teniendo yglesias deviseras de tiempos inmemoriales..." 125 . Es decir, una de las piezas claves que utilizaron para justificar la superioridad y antigüedad de su nobleza frente a los procuradores de las Juntas Generales que prohibían sus reuniones era el disfrute de los derechos de patronato. Pero desde entonces esto se convirtió apenas en un reiterado argumento. Aun reclamándose vasallos del rey y disfrutando de derechos cedidos por él, las nuevas circunstancias los alejaron definitivamente de la nueva articulación política que estaba cuajando en Guipúzcoa y, si bien continuaron manteniendo los ingresos procedentes del patronato sobre las iglesias, los instrumentos del control social y político de las universidades y villas guipuzcoanas estaban pasando a otras manos.

${ }^{125}$ A.G.G., Secc. 1, Neg. 6, Leg. 18 (1518.21 de abril). 


\begin{tabular}{|c|c|c|c|c|c|c|c|c|c|c|c|c|c|c|c|}
\hline 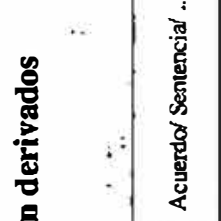 & $\begin{array}{l}\circ \\
\frac{5}{2} \\
\frac{3}{2}\end{array}$ & $\begin{array}{l}\text { 总 } \\
\stackrel{0}{2}\end{array}$ & 递 & 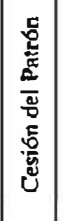 & 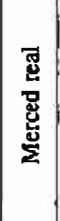 & 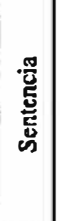 & 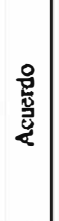 & $\begin{array}{l}\text { 总 } \\
\text { 恖 }\end{array}$ & 謍 & 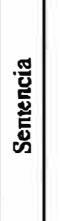 & 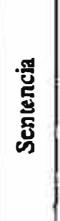 & $\begin{array}{l}0 \\
\stackrel{2}{2} \\
\frac{3}{4}\end{array}$ & $\begin{array}{l}\circ \\
\stackrel{8}{\mathrm{~d}} \\
\stackrel{3}{4}\end{array}$ & 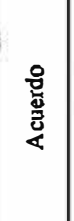 & 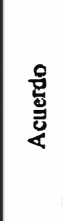 \\
\hline 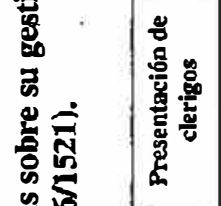 & 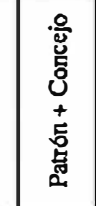 & 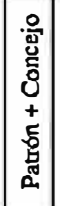 & 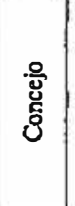 & $\left|\begin{array}{l}0 \\
\tilde{\mathscr{c}} \\
\tilde{c} \\
c \\
c\end{array}\right|$ & 点 & 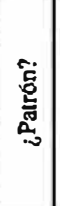 & 害 & 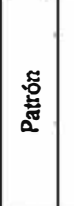 & 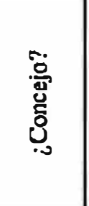 & \begin{tabular}{l}
.0 \\
\hdashline \\
0 \\
0 \\
0
\end{tabular} & 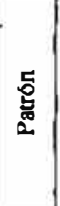 & $\begin{array}{l}\text { 䓌 } \\
\text { 总 }\end{array}$ & 镸 & 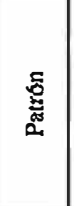 & 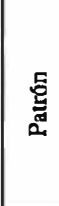 \\
\hline 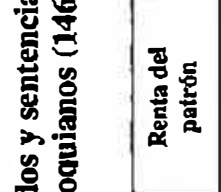 & 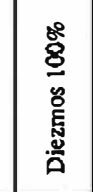 & 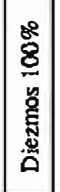 & 点 & $\varepsilon^{\circ}$ & 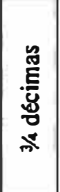 & 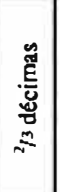 & 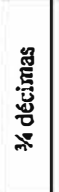 & 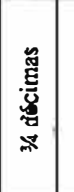 & 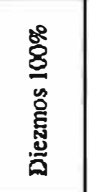 & 今̊ & $8^{\circ}$ & 8 & 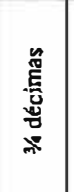 & 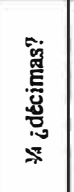 & 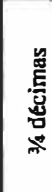 \\
\hline 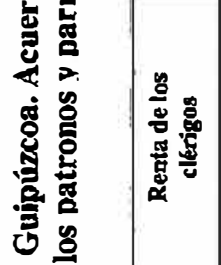 & 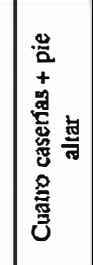 & 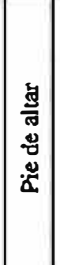 & so & 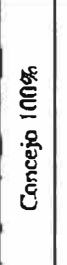 & 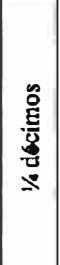 & 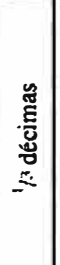 & 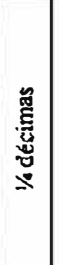 & 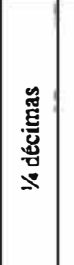 & 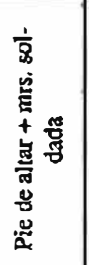 & s: & $8^{\circ}$ & $\stackrel{8}{8}$ & 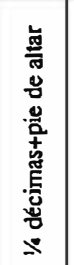 & 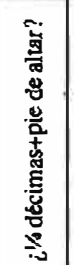 & 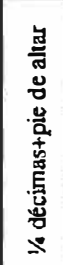 \\
\hline 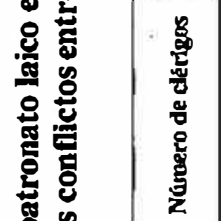 & 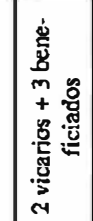 & 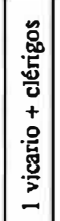 & 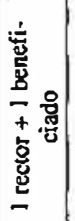 & is & $\because$ & 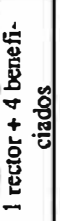 & 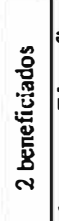 & 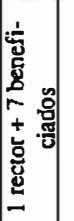 & $\begin{array}{l}\text { 品 } \\
\text { 密 }\end{array}$ & $?$ & 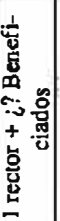 & 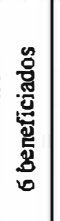 & 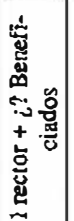 & 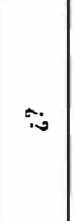 & 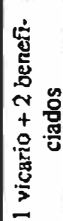 \\
\hline $\bar{z}$ & $\frac{8}{9}$ & 急 & E & 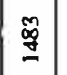 & 总 & 嘿 & 8 & $\stackrel{g}{g}$ & 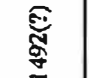 & 曽 & 菷 & $\bar{\sigma}$ & 号 & 莺 & $\bar{\Xi}$ \\
\hline 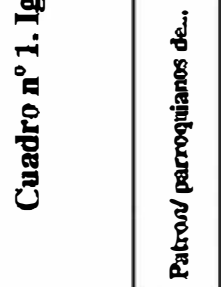 & 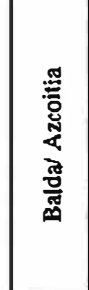 & 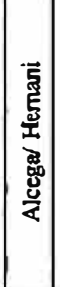 & 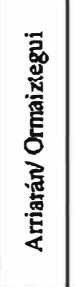 & 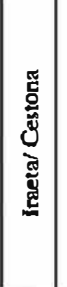 & 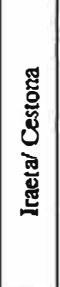 & 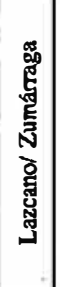 & 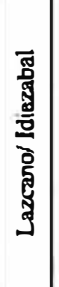 & 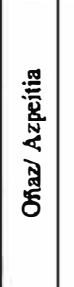 & 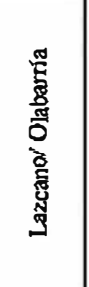 & 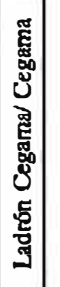 & 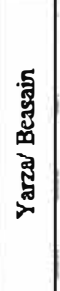 & 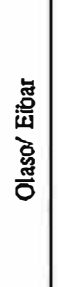 & 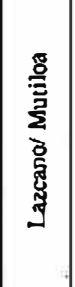 & 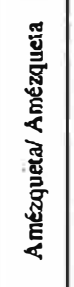 & 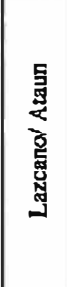 \\
\hline
\end{tabular}

La Epoca de Felipe Il y los Austrias Hispanja Sacra 50 (1998) 